\title{
KULEUVEN
}

DEPARTMENT OF ECONOMICS

\section{Road tolls, diverted traffic and local traffic calming measures: who should be in charge?}

Bruno DE BORGER and Stef PROOST

FACULTY OF ECONOMICS AND BUSINESS
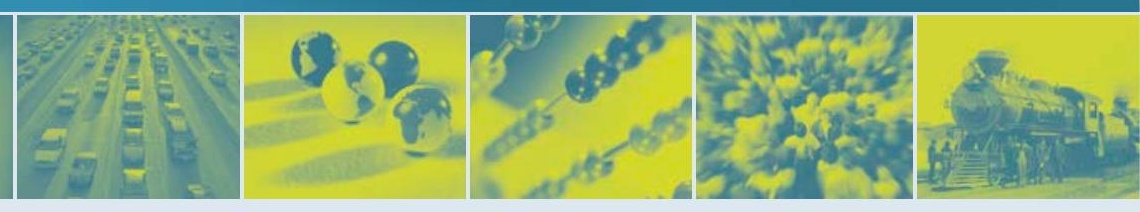

DISCUSSION PAPER SERIES DPS18.12

OCTOBER 2018 


\title{
Road tolls, diverted traffic and local traffic calming measures:
}

\author{
who should be in charge?
}

\section{Bruno De Borger and Stef Proost (*)}

\begin{abstract}
The paper studies the traffic problems of a small town that is located parallel to a motorway and faces through traffic. We assume that the federal government can control traffic levels on the motorway using tolls, whereas a local government controls local accident risks and congestion using non-price measures such as speed bumps, traffic lights and explicit access restrictions for through traffic. We show the following results. First, competition between the federal and local authority leads to a Nash equilibrium where the toll is too high and there is too much traffic calming compared to the second-best social optimum. Second, if the local government uses traffic calming measures, imposing a federal toll on the main road is welfarereducing, unless congestion on the main road is severe and accident risks in the small town are unimportant. Third, traffic diverted from the main road to the local community gives the latter strong incentives to close the local road for through traffic, even when it is socially undesirable to do so. In this sense, granting authority over such drastic local traffic calming measures to local governments may be welfare-reducing. Fourth, if the access restriction only applies to through traffic by trucks, the conflict between federal and local authorities disappears: both will agree on prohibiting access to trucks, unless they have the local town as final destination. Finally, we find that the inefficiency of vertical competition between local and federal governments can largely be avoided by introducing a hierarchy of roads and having separate independent agencies negotiate over tolls and traffic calming measures.
\end{abstract}

JEL-codes: D62, H21, H23, H77, R41

Keywords: Traffic access control, traffic calming, traffic externalities, competition between governments

(*) Bruno De Borger, Department of Economics, University of Antwerp, Belgium (bruno.deborger@uantwerpen.be); Stef Proost, Center for Economic Studies, KULeuven, Belgium (stef.proost@kuleuven.be). We are grateful to the Flemish Fund for Scientific Research for financial support. 


\section{Introduction}

This paper studies a problem that is quite common in many European countries. Consider a small town or municipality that is located parallel to a motorway or other major road. The municipality faces two types of traffic. Some traffic has the municipality as final destination; this includes traffic for local deliveries, shopping, local employment, schools, etc. However, there is also 'diverted' traffic; this is traffic that avoids congestion on the main road by taking a local road that passes through the municipality. Diverted traffic contributes to increased congestion on the local road, and it generates accident risks and other inconveniences for the local population.

We define a two-road network and study the competition between a 'federal' and a local government that each operate part of the network, using different policy instruments. This is quite realistic: most countries have a road system where different types of roads are operated by different authorities. ${ }^{1}$ We assume the federal government controls traffic on the main road using a congestion toll (possibly equal to zero). A local government uses different types of access restrictions to reduce local congestion and to limit accident risks and local nuisances for the population in the small community. The instruments they use include standard traffic calming measures (speed bumps, traffic lights, speed limits) but also formal access restrictions (i.e., restrictions on who is allowed to use a particular road). These may include prohibiting access to through traffic, a ban on through traffic by trucks, etc.

High congestion levels on many major roads and recent technological developments imply that the policy instruments we study in this paper are likely to become very popular in the near future. First, economists have long advocated tolling as an efficient instrument to tackle congestion, and the use of congestion tolls is slowly taking off, mainly in urban areas (see Anas and Lindsey (2011)). There are no technical impediments to a more widespread implementation of tolls in the future; moreover, the positive effects of existing pricing examples in London, Stockholm and Milan is slowly reducing political opposition towards congestion charges. Second, traffic calming measures such as traffic lights and speed bumps are already frequently used by local governments. Importantly, although in the past explicit access restrictions were difficult to enforce, recent developments in the technology of number plate recognition make it possible to organize a selective access to certain areas. In fact, restricted entry systems are already gaining popularity. The official EU-website www.urbanaccessregulation.eu reports that in Europe (as of July 2017) there were 559 access regulations in urban areas. These included

\footnotetext{
${ }^{1}$ For example, highways and other major roads may be operated at the national level, intermediate roads by regional governments and local roads by municipalities.
} 
250 low emission zones, but the majority (278) were other types of access restrictions, such as not allowing trucks on part of the network, reserving part of the network for residents, not allowing some types of traffic at particular times of the day, etc. ${ }^{2}$ The restrictions are enforced by cameras, physical barriers, police, or by local authority officers. The technological progress in Automatic Number Plate Recognition (ANPR) cameras allows to enforce the traffic calming measures at much lower cost than in the past, when continuous police control was necessary.

Note that in principle camera detection technologies might also be used to implement tolls on local roads. Although different non-zero tolls on national and local roads are economically efficient (see, for example, de Palma and Lindsey (2000)), they are very uncommon. Apart from technical reasons, there are good political economy reasons why they are also unlikely to be used in the future. Constitutional restrictions often prevent the federal government to set tolls that are different between regions, because the political process would lead to exploitation of one region by other regions (see De Borger and Proost (2016b)). Moreover, granting authority over local tolls to local governments is equally undesirable, because it would imply inefficient tax exporting behavior. We therefore assume the local government cannot implement a toll on the municipal road; it only uses traffic calming and access restrictions.

The competition between the federal and local governments raises a number of interesting issues. First, how does the toll the federal authority imposes on the main road affect the use of traffic calming measures by the local community? Vice versa, conditional on the number of speed bumps and traffic lights in the local town, how will the higher level government determine the toll on the main road? Second, how does the Nash equilibrium compare to the second-best optimal decisions on tolls and traffic calming measures? Will the toll be too high or too low? Will there be insufficient or excessive traffic calming? Third, given the use of traffic calming measures by the local government, is it actually a good idea for the federal government to introduce a toll on the main road, or is doing so welfare-reducing? Fourth, will the possibility of using new technologies to restrict access to certain types of traffic not lead to a proliferation of abuses, in the sense that many local governments will restrict access even when it is socially undesirable to do so?

We find several results. First, implementing the first-best would require the use of three instruments: a toll on the main road, a toll on the local road, and the introduction of traffic

\footnotetext{
2 These ‘other' restrictions are referred to as ‘traffic restrictions', 'limited traffic zones', ‘access restrictions', 'other entry restrictions', 'permit schemes', etc. Note that the website mentioned above only reveals the top of the iceberg of traffic restrictions, because the contribution to this website is voluntary. An increasing number of such restrictions are very local and not captured in the figures on the website. For example, many municipalities ban trucks, except for local delivery, others have introduced car-free zones in some areas, etc.
} 
calming measures. If we assume - for technical or political reasons - that a toll on the local road is not feasible, the second-best social optimum implies a lower toll on the main road but more local traffic calming as compared to the first-best. Second, turning to competition between local and federal governments, the reaction functions of both authorities are positively sloped: higher tolls on the main road induce more traffic calming by the local community, and more traffic calming leads to higher tolls. The Nash equilibrium gives a toll that is too high and too much traffic calming compared to the second-best social optimum. Third, the existence of diverted traffic from the main road to the local community gives the latter strong incentives to close the local road for through traffic, even when it is socially undesirable to do so. In this sense, there exists a potential conflict between the local and federal interest, and granting authority over local traffic calming measures to local governments may be welfare-reducing. Interestingly, however, there is no such conflict when the access restrictions apply to through traffic by trucks only. With implementation costs that are quickly declining due to technological improvements, both the federal and local governments will agree to put a ban on truck access to local communities. Finally, we find that some of the inefficiencies of vertical competition between local and federal governments can be avoided by introducing a hierarchy of roads, with separate public agencies bargaining over tolls and traffic calming measures.

Structure of the paper is as follows. Section 1 briefly reviews the literature. Section 2 sets up a simple network consisting of a major road and a local side road that passes through a local community. If the highway is very congested and no measures are taken, traffic has the opportunity to pass through the local community, where they cause congestion as well as accident externalities on the local population. Section 3 derives the first- and second best social optima. In Section 4 we analyze the competition between the federal and local authority. Section 5 zooms in on the appropriate division of authority between the local and the federal government. In Section 6 we examine the incentives for the federal and local authorities to close down the local road for all through traffic, or for through traffic by trucks only. Section 7 discusses limitations and possible extensions of the model. A final section concludes.

\section{Review of the literature}

Economists have long focused on controlling transport externalities by using pricing instruments. A very large literature on optimal tolls has developed, both on single roads and on simple networks of parallel roads under different institutional settings (examples include, among many others, Verhoef, Nijkamp and Rietveld (1996), de Palma and Lindsey (2000), De 
Borger, Proost, and Van Dender (2005), and Ubbels and Verhoef (2008)). ${ }^{3}$ Surprisingly, although - as shown in the introduction - non-pricing measures are much more popular than road tolls, they have not received much attention in the economics literature. Policy makers and transport planners have been much more interested in traffic calming and access restrictions than the transport economics community. For example, the literature on transport planning devotes quite some attention to car-free zones in cities, emphasizing the health benefits of carfree cities (see, for example, Van Nieuwenhuysen and Khreis (2016)). ${ }^{4}$

The scarce economics literature on non-price measures is easily reviewed. First, several papers explore the effectiveness of Low Emission Zones in developed economies, mainly focusing on pollution benefits (see, e.g., Wolff and Perry (2010)). Second, a more extensive literature studies the effects of low-tech car access restrictions, such as alternating between allowing access to cars with even and uneven number plates. These policies have become quite popular in developing countries. In an early study, Davis (2008) found no evidence that the policy improved air quality in Mexico-city, because it increased car ownership and added more polluting cars to the stock. Nie (2017) jointly considered tradeable driving rights and restrictions of the even/uneven number plate type. Third, traffic calming measures were studied in an early paper by Elvik (2001), but the emphasis was not on the economic desirability of such measures. The economics of traffic calming were more recently analyzed in De Borger and Proost (2013). They studied the traffic externalities on a single road through a local community. The local community wants to limit transiting traffic using two types of non-price measures: (i) measures that reduce local externalities but at the same time increase the user cost for all cars (speed bumps, traffic lights); (ii) measures that reduce external costs but do not affect the user costs of cars (pedestrian bridges, ring roads). In a follow-up paper, Proost and Westin (2016) studied the competition in traffic calming measures between two parallel suburbs, showing that this gave rise to a 'race to the top'. Fourth, the efficiency of imposing speed limits have been studied by Nitzsche and Tscharaktschiew (2013) within a general equilibrium land-use model. They look at the relative efficiency of general speed limits and more localized speed limits, taking into account the relocation of trips and activities within a metropolitan area. They found that localized measures are more effective. Finally, Van Benthem (2015) derived the optimal speed limit and discussed the implications for cost-benefit analysis of road projects.

\footnotetext{
${ }^{3}$ For surveys, see Anas and Lindsey (2011) and De Borger and Proost (2012). Note that there also exists a large literature on the use of other pricing instruments such as fuel taxes (examples include Parry and Small (2005), and Bento et al. (2009)).

${ }^{4}$ The World Economic Forum has also promoted the benefits of car-free zones within cities, recognizing that 13 cities (including Oslo and Madrid) have made substantial progress in banning cars.
} 
Compared to the literature, this paper has three distinct characteristics. First, it focuses on managing local traffic problems in a small network in the presence of diverted traffic, and using both tolling on the main road and local non-price traffic calming measures as instruments. Second, it studies the implications of formal access restrictions at the local level. Third, it provides a detailed analysis of the competition between two levels of government: a federal authority controlling tolls, and a local government focusing on traffic calming or explicit access restrictions.

\section{Model description: demand, costs and user equilibrium}

We first describe the network and the different types of traffic considered. Next we discuss the demand functions, the generalized costs on the various links of the network, and the accident externalities. Moreover, we review the policy instruments available to the different governments. Finally, we present the user equilibrium, and we formulate the welfare functions used to evaluate government policies.

The network. We consider a simple network (see Figure 1 for an illustration). It consists of a major road $O D$ and a secondary road that passes through a local community. People in the local municipality live in $L$, and location $C$ can be interpreted as a local destination (such as a shopping or school area). Location $D$ can be interpreted as an employment center where much commuting has its destination. Finally, location $O$ is a major residential area that generates much traffic to the employment area.

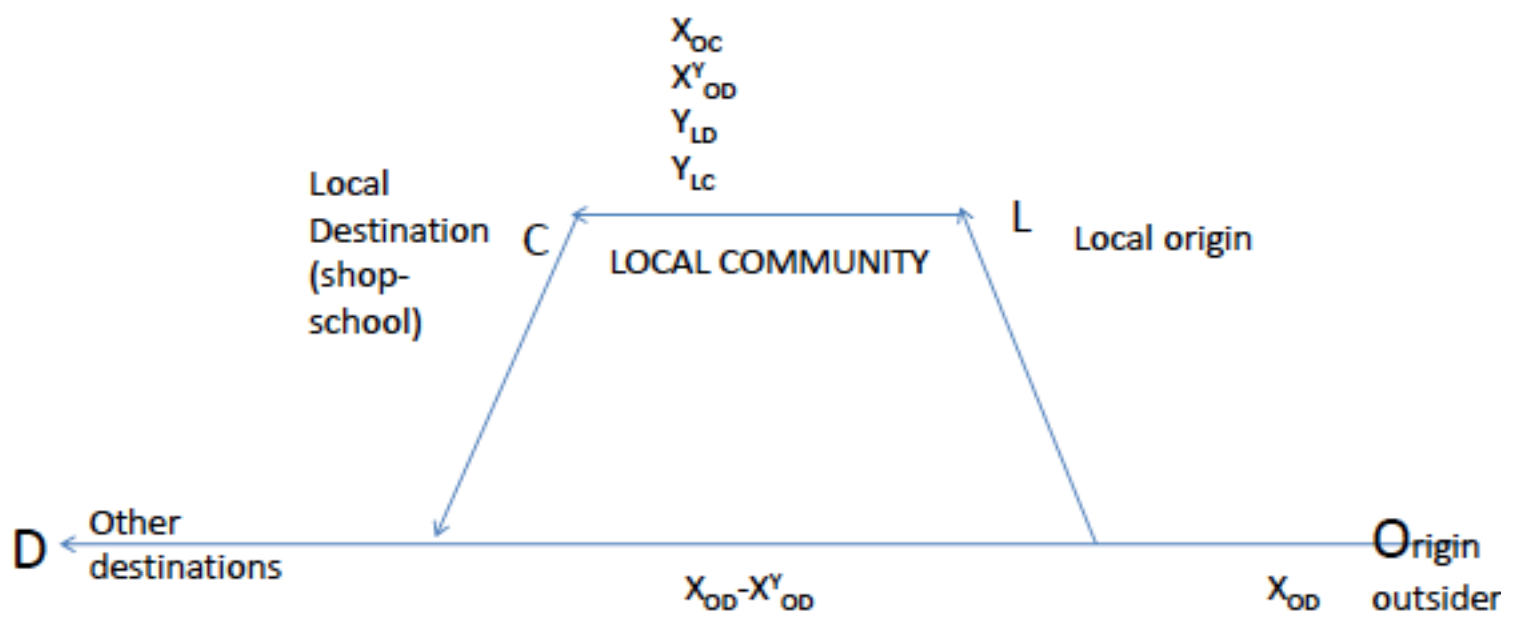

Figure 1. Structure of the network 
The model studies the peak-period only, and it emphasizes the problems caused by traffic that is diverted from the main road and passes through the municipality. We therefore assume for simplicity that total commuting demand is fixed, but commuters from $O$ to $D$ do have route choice. Moreover, without loss of generality and in order to focus on the main tradeoffs of interest, we normalize the distances $C D$ and $O L$ to zero.

Turning to specifics, traffic originating from $O$ is denoted $X$, and traffic originating from the local community is denoted $Y$. Commuting traffic by outsiders (they drive from $O$ to $D$ ) and by local inhabitants of the municipality that work in $D$ (hence, traffic from $L$ to $D$ ) are denoted by $\bar{X}_{O D}, \bar{Y}_{L D}$, respectively. The vertical bar indicates that these traffic levels are exogenous and fixed. Moreover, both locals and outsiders make some trips that have the local community as final destination; this generates traffic from $L$ to $C$ and from $O$ to $C$, respectively. We denote this non-commuting traffic by $X_{O C}, Y_{L C}$, respectively. This traffic is assumed to be priceresponsive, see below.

Importantly, as emphasized above, traffic from $O$ to $D$ has route choice; they can go via the main road or through the local community. The use of this local road suffers from potentially large external costs when many drivers between $O$ and $D$ take the detour via the suburb to avoid congestion on the main road. We denote the number of cars driving from $O$ to $D$ that are diverted from the main road and drive through the local municipality $X_{O D}^{y}$; the remainder, equal to $\bar{X}_{O D}-X_{O D}^{y}$, uses the main road. In Table 1 we summarize the different types of traffic, the notation used, and the assumptions made. 


\begin{tabular}{|l|l|l|}
\hline Type of traffic & $\underline{\text { Notation }}$ & $\underline{\text { Remarks }}$ \\
\hline $\begin{array}{l}\text { Commuting from O to } \\
\text { D (outsiders) }\end{array}$ & $\bar{X}_{O D}$ & Fixed \\
\hline $\begin{array}{l}\rightarrow \text { Via local community: } \\
\text { secondary road } y\end{array}$ & $X_{O D}^{y}$ & $\begin{array}{l}\text { Depends on generalized } \\
\text { cost } x \text { versus } y\end{array}$ \\
\hline$\rightarrow$ Via main road $x$ & $\bar{X}_{O D}-X_{O D}^{y}$ & $\begin{array}{l}\text { Depends on generalized } \\
\text { cost } x \text { versus } y\end{array}$ \\
\hline $\begin{array}{l}\text { Commuting from L to } \\
\text { D (locals) }\end{array}$ & $\bar{Y}_{L D}$ & Fixed \\
\hline $\begin{array}{l}\text { Non-commuting from } \\
\text { O to C (outsiders) }\end{array}$ & $X_{O C}$ & Price-responsive \\
\hline $\begin{array}{l}\text { Non-commuting from } \mathbf{L} \\
\text { to C (locals) }\end{array}$ & $Y_{L C}$ & Price-responsive \\
\hline
\end{tabular}

Table 1: notation and assumptions on types of traffic

Demand, costs and accident externalities. Commuting demand is fixed, as mentioned above.

Demand for $X_{O C}, Y_{L C}$ is price-responsive. To simplify, we assume demands are proportional:

$$
Y_{L C}=\rho X_{O C}
$$

This is a strong assumption, because it implies that the maximum willingness to pay of both types of road users is the same. However, it much simplifies the analysis, because it implies that a single demand function can be used, and only the proportion of local traffic versus traffic by outsiders varies. We specify demand by the inverse demand function:

$$
P=a-b\left(X_{O C}+Y_{L C}\right)=a-b(1+\rho) X_{O C} .
$$

There are two types of externalities. First, on both the main road and the local road there is congestion, captured by linear congestion functions. Second, traffic passing via the local road causes accident, noise and local air pollution externalities for the local population (residents, pedestrians, bikers, playing children, etc.).

We also consider two sets of policy instruments. A toll can be levied on the main road (controlled by the federal authority); moreover, the local government may have the authority to implement traffic calming measures on the road passing through the local community. We denote the investment in such measures by $Z$. Traffic calming has two potential effects: it may increase the generalized cost of passing through the local community (because it slows down traffic), and it reduces the accident risk and other inconveniences for the local population. The toll we consider is a simple uniform peak-period toll; it only affects the volume of road traffic in the peak, but it does not vary over time and cannot be personalized. 
We denote traffic via the main road by index $x$, via the local road by index $y$. The generalized costs of using the main road and the local road are written as:

$$
\begin{aligned}
& G C_{x}=\alpha_{x}+\beta_{x}\left(\bar{X}_{O D}-X_{O D}^{y}\right)+\tau_{x} \\
& G C_{y}=\alpha_{y}+\left(\beta_{y}+\delta Z\right)\left(X_{O D}^{y}+(1+\rho) X_{O C}+\bar{Y}_{L D}\right)
\end{aligned}
$$

The generalized cost via $x$ depends on all traffic taking this route; this is all traffic from $O$ to $D$ minus the traffic $X_{O D}^{y}$ that is diverted to the municipal secondary road $y$. The toll is denoted $\tau_{x}$. The generalized cost via $y$ depends on all flows passing through $y$ : all traffic originating from the local community $L\left(Y_{L C}, \bar{Y}_{L D}\right)$, traffic from $O$ to $D$ but taking the secondary road $\left(X_{O D}^{y}\right)$, and traffic from $O$ with $C$ as final destination $\left(X_{O C}\right)$. The parameter $\delta$ captures the degree to which investing in traffic calming affects congestion on the secondary road through the local community. For example, speed bumps or traffic lights slow down traffic and lead to extra delays.

The congestion externality is captured via the slope parameters $\beta_{x}, \beta_{y}$. The cost of accident risks and local nuisances for the municipal population is formulated as a function of the traffic volume and the traffic calming measures $Z$ :

$$
(\lambda \theta(1-\gamma Z))\left(X_{O D}^{y}+(1+\rho) X_{O C}+\bar{Y}_{L D}\right)
$$

It consists of the product of the expected cost of accidents and other nuisances $(\lambda \theta(1-\gamma Z))$ times the total traffic volume though the local community $\left(X_{O D}^{y}+(1+\rho) X_{O C}+\bar{Y}_{L D}\right)$. To understand the expected cost per extra car through the local town, let us think for concreteness of accident externalities traffic imposes on the local population. The first two parameters then capture the accident cost per accident $(\lambda)$ and the probability of an accident $(\theta)$, respectively. In the case of pollution of other nuisances, the expected external cost per unit extra traffic is $\lambda \theta$. Do note that the expected cost can be reduced by government policy: investing in traffic calming $Z$ reduces the expected cost of accidents or other nuisances; the parameter $\gamma$ captures the effectiveness of traffic calming in reducing these costs. An analogous formulation can be used for the cost of local health incidence and the probability of local health incidence.

Our formulation allows to model a large diversity of traffic calming measures. We summarize them in Table 2. Denoting the implementation cost by $c$, the table illustrates that by considering various combinations of the parameters $(\delta, \gamma, c)$, we can represent a wide variety of traffic calming policies. 


\begin{tabular}{|l|l|l|l|}
\hline \multicolumn{1}{|c|}{ Traffic calming measure } & \multicolumn{1}{|c|}{$\begin{array}{c}\text { Effect on } \\
\text { congestion } \\
(Z)\end{array}$} & \multicolumn{1}{|c|}{$\begin{array}{c}\text { Reduction in } \\
\text { local external } \\
\text { effect } \\
(\gamma)\end{array}$} & $\begin{array}{c}\text { Implementation } \\
\text { cost for local } \\
\text { government } \\
(c)\end{array}$ \\
\hline Speed limit & High & Medium & Low \\
\hline Speed bumps & High & Medium & Medium \\
\hline Traffic lights & High & Medium & Low \\
\hline Pedestrian bridge-tunnel & None & High (accidents) & High \\
\hline Cycling paths & None & High (accidents) & High \\
\hline Low Emission Zone & Medium & High (pollution) & High \\
\hline No through traffic & High & High & Medium \\
\hline No access for trucks & Medium & Medium & Medium \\
\hline
\end{tabular}

\section{Table 2. Characteristics of different traffic calming measures}

Initial user equilibrium._We assume the split of traffic from $O$ to $D$ between routes $x$ and $y$ is governed by the Wardrop condition so that, if both routes are used in equilibrium, they must have equal generalized costs ${ }^{5}$. Moreover, for price-responsive demand it must be the case that, in equilibrium, generalized price (or willingness to pay) equals generalized cost. We therefore have the following equilibrium conditions for the split between the main and the local road and for the traffic level on the local road, respectively:

$$
\begin{aligned}
& \alpha_{x}+\beta_{x}\left(\bar{X}_{O D}-X_{O D}^{y}\right)+\tau_{x}=\alpha_{y}+\left(\beta_{y}+\delta Z\right)\left(T^{y}\right) \\
& a-b(1+\rho) X_{O C}=\alpha_{y}+\left(\beta_{y}+\delta Z\right)\left(T^{y}\right)
\end{aligned}
$$

where $T^{y}$ is total traffic via the local community $y$ :

$$
T^{y}=X_{O D}^{y}+(1+\rho) X_{O C}+\bar{Y}_{L D} .
$$

Solving this system we get the user equilibrium flows:

$$
\begin{aligned}
& X_{O D}^{y}=\left(\frac{1+\rho}{\Delta}\right)\left\{\bar{X}_{O D}\left[\beta_{x}\left(b+\beta_{y}+\delta Z\right)\right]-\bar{Y}_{L D} b\left(\beta_{y}+\delta Z\right)+b\left(\tau_{X}+\alpha_{x}-\alpha_{y}\right)-\left(\beta_{y}+\delta Z\right)\left(a-\tau_{x}-\alpha_{X}\right)\right\} \\
& X_{O C}=\left(\frac{-1}{\Delta}\right)\left\{\beta_{x}\left(\beta_{y}+\delta Z\right)\left(\bar{X}_{O D}+\bar{Y}_{L D}\right)-\beta_{x}\left(a-\alpha_{y}\right)-\left(\beta_{y}+\delta Z\right)\left(a-\tau_{x}-\alpha_{X}\right)\right\}
\end{aligned}
$$

where

\footnotetext{
${ }^{5}$ Corner solutions could be considered where the generalized cost on the local road is always higher than on the main road (or vice versa), but this does not give additional insights.
} 


$$
\Delta=(1+\rho)\left[\beta_{x} b+\left(b+\beta_{x}\right)\left(\beta_{y}+\delta Z\right)\right]>0 .
$$

It will be useful to consider the effect of the policy variables on demands. Differentiating (6), the effects of increasing traffic calming $Z$ are:

$$
\begin{aligned}
& \frac{\partial X_{O D}^{y}}{\partial Z}=-\frac{(1+\rho)^{2} \delta b}{\Delta^{2}}(H)<0 \\
& \frac{\partial X_{O C}}{\partial Z}=-\frac{(1+\rho) \delta \beta_{x}}{\Delta^{2}}(H)<0 \\
& \frac{\partial T^{y}}{\partial Z}=\frac{\partial X_{O D}^{y}}{\partial Z}+(1+\rho) \frac{\partial X_{O C}}{\partial Z}=-\frac{(1+\rho)^{2} \delta}{\Delta^{2}}\left[\left(b+\beta_{x}\right)(H)\right]<0
\end{aligned}
$$

where

$$
(H)=b \beta_{x}\left(\bar{X}_{O D}+\bar{Y}_{L D}\right)+b\left(\tau_{x}+\alpha_{x}-\alpha_{y}\right)+\beta_{x}\left(a-\alpha_{y}\right)>0 .
$$

Expressions (7) show that traffic calming on route $y$ can be an effective instrument to reduce diverted traffic. By increasing the generalized cost, it also reduces price-sensitive demand $X_{O C}$. Total demand using road $y$ necessarily declines.

The effect of the toll on the main road on equilibrium demands for use of the local road is:

$$
\begin{aligned}
& \frac{\partial X_{O D}^{y}}{\partial \tau_{x}}=\frac{(1+\rho)\left(b+\beta_{y}+\delta Z\right)}{\Delta}>0 \\
& \frac{\partial X_{O C}}{\partial \tau_{x}}=-\frac{\left(\beta_{y}+\delta Z\right)}{\Delta}<0 \\
& \frac{\partial T^{y}}{\partial \tau_{x}}=\frac{\partial X_{O D}^{y}}{\partial \tau_{x}}+(1+\rho) \frac{\partial X_{O C}}{\partial \tau_{x}}=\frac{(1+\rho) b}{\Delta}>0
\end{aligned}
$$

The toll raises traffic from $O$ to $D$ that goes via the local road, and it decreases the demand for traffic on that road with a local destination as a consequence: congestion increases, and demand with a local destination is price-sensitive. Total traffic on the local road increases: the first effect dominates the second.

At this point it is useful to get back to the different types of traffic calming measures mentioned in Table 2. Specifically, consider measures that have no effect on local congestion, such as pedestrian bridges or separate cycling paths. In that case $\delta=0$; it then follows from (7) that these measures have no effect whatsoever on traffic flows on the network. Other measures (traffic lights, speed bumps, speed limits) do slow down traffic $(\delta>0)$ and affect all demands for the local road. 
Welfare. There is a higher level government that cares for all road users; it also cares for the accident risks and other nuisances experienced by the inhabitants of the local municipality. The objective function of this 'federal' government is the sum of consumer surplus for pricesensitive traffic minus all generalized costs, plus toll revenues minus the costs of traffic calming measures, minus external costs:

$$
\begin{gathered}
\int_{0}^{(1+\rho) X_{O C}} P(q) d q-G C_{x}\left(\bar{X}_{O D}-X_{O D}^{y}\right)-G C_{y}\left(T^{y}\right)+\tau_{x}\left(\bar{X}_{O D}-X_{O D}^{y}\right) \\
-0.5 c Z^{2}-(\lambda \theta(1-\gamma Z))\left(T^{y}\right)
\end{gathered}
$$

Using our demand specification (2) and the equilibrium conditions (4) this can, after simple algebra, be rewritten as:

$$
\begin{gathered}
\frac{b}{2}\left[(1+\rho) X_{O C}\right]^{2}-\left[\alpha_{x}+\beta_{x}\left(\bar{X}_{O D}-X_{O D}^{y}\right)\right]\left(\bar{X}_{O D}+\bar{Y}_{L D}\right)+\tau_{x}\left(\bar{X}_{O D}-X_{O D}^{y}\right) \\
-0.5 c Z^{2}-(\lambda \theta(1-\gamma Z))\left(T^{y}\right)
\end{gathered}
$$

A local government defends the interests of the inhabitants of the local municipality. It only considers the surplus and the generalized costs for the local population, ignoring the effect on outsiders $^{6}$. Its objective function is:

$$
\frac{\rho}{1+\rho} \int_{0}^{(1+\rho) X_{O C}} P(q) d q-G C_{y}\left(Y_{L C}+\bar{Y}_{L D}\right)-0.5 c Z^{2}-(\lambda \theta(1-\gamma Z))\left(T^{y}\right) .
$$

Straightforward algebra shows that it can be rewritten as:

$$
\frac{b}{2} \frac{1+\rho}{\rho}\left(Y_{L C}\right)^{2}-G C_{y}\left(\bar{Y}_{L D}\right)-0.5 c Z^{2}-(\lambda \theta(1-\gamma Z))\left(T^{y}\right)
$$

\section{The first- and second-best social optima}

In this section, as a reference point for the discussion on government competition, we first study the first- and second-best social optima.

\subsection{The first-best}

The first-best directly controls the traffic levels $X_{O D}^{y}, X_{O C}$ and the level of traffic calming. It is the solution, of

\footnotetext{
${ }^{6}$ In reality, of course, traffic with the local community as final destination does bring benefits to the local community in the form of, e.g., extra activities for local shopkeepers, etc. In the current model focusing on commuting traffic having route choice, these potential benefits are ignored.
} 
$\underset{X_{O D}^{y}, X_{O C}, Z}{\operatorname{Max}} \int_{0}^{(1+\rho) X_{O C}} P(q) d q-G C_{x}\left(\bar{X}_{O D}-X_{O D}^{y}\right)-G C_{y}\left(T^{y}\right)-0.5 c Z^{2}-(\lambda \theta(1-\gamma Z))\left(T^{y}\right)$

The first-order conditions give us, after straightforward algebra, the following three equations:

$$
\begin{aligned}
& P=\alpha_{y}+2\left(\beta_{y}+\delta Z\right)\left(T^{y}\right)+\lambda \theta(1-\gamma Z) \\
& \alpha_{x}+2 \beta_{x}\left(\bar{X}_{O D}-X_{O D}^{y}\right)=\alpha_{y}+2\left(\beta_{y}+\delta Z\right)\left(T^{y}\right)+\lambda \theta(1-\gamma Z) \\
& \lambda \theta \gamma\left(T^{y}\right)=c Z+\delta\left(T^{y}\right)^{2}
\end{aligned}
$$

The interpretation is easy. The first equation requires the generalized price $P$ of traveling via $y$ to equal the marginal social cost, consisting of the generalized cost plus the marginal external cost (congestion plus local pollution and accident) of using road $y$; this equals $\left(\beta_{y}+\delta Z\right)\left(T^{y}\right)+\lambda \theta(1-\gamma Z)$. The second equation says that the marginal social costs of going via $x$ or $y$ should be equal. The third expression states equality between the marginal benefit (left-hand side) and the marginal cost (right-hand side) of investment in traffic calming $Z$. The marginal cost consists of the marginal cost of installing the traffic calming measures plus the extra congestion cost it induces. Note that the first-best may imply zero flows for some types of traffic. For example, when the accident externalities are very large even for very small volumes, the optimal solution is a corner solution that does not allow car traffic on $y$.

Implementation of the first-best is straightforward in theory. Suppose the planner has tolls $\tau_{x}, \tau_{y}$ on $x$ and $y$ at its disposal and that, in addition, it can optimize traffic calming. Using the two tolls to control traffic flows, and traffic calming to optimize the level of the externality for the local community, leads to the first-best outcome. To see this, maximize welfare (taking into account toll revenues) with respect to the tolls and traffic calming:

$$
\begin{array}{r}
\operatorname{Max}_{\tau_{x}, \tau_{y}, Z} \quad W^{f}=\int_{0}^{(1+\rho) X_{O C}} P(q) d q-G C_{x}\left(\bar{X}_{O D}-X_{O D}^{y}\right)-G C_{y}\left(T^{y}\right) \\
\quad-0.5 c Z^{2}-\lambda \theta(1-\gamma Z)\left(T^{y}\right)+\tau_{x}\left(\bar{X}_{O D}-X_{O D}^{y}\right)+\tau_{y}\left(T^{y}\right)
\end{array}
$$

The solution yields - where, to arrive at the third one, we used the optimal toll expressions the following three conditions:

$$
\begin{aligned}
& \tau_{x}=\beta_{x}\left(\bar{X}_{O D}-X_{O D}^{y}\right) \\
& \tau_{y}=\left(\beta_{y}+\delta Z\right)\left(T^{y}\right)+\lambda \theta(1-\gamma Z) \\
& \lambda \theta \gamma\left(T^{y}\right)=c Z+\delta\left(T^{y}\right)^{2}
\end{aligned}
$$

Tolls equal marginal external cost on both roads. Using these tolls in the user equilibrium conditions, simple algebra shows that we reproduce all first-best conditions given above. Note 
that we need three instruments to implement the optimum: the tolls determine total demand and the allocation between the two roads, traffic calming on the local road determines the level of the local externality, conditional on the traffic level.

\subsection{The second-best social optimum}

Reconsidering (12) but assuming a local toll $\tau_{y}$ cannot be implemented, we have the first-order conditions (after rearrangement):

$$
\begin{gathered}
\left(\tau_{x}-\beta_{x}\left(\bar{X}_{O D}-X_{O D}^{y}\right)\right) \frac{\partial X_{O D}^{y}}{\partial \tau_{x}}+\left\{\left[\left(\beta_{y}+\delta Z\right)\left(T^{y}\right)+\lambda \theta(1-\gamma Z)\right]\left[\frac{\partial T^{y}}{\partial \tau_{x}}\right]\right\}=0 \\
-\left(\tau_{x}-\beta_{x}\left(\bar{X}_{O D}-X_{O D}^{y}\right)\right) \frac{\partial X_{O D}^{y}}{\partial Z}-\left[\left(\beta_{y}+\delta Z\right) T^{y}+\lambda \theta(1-\gamma Z)\right]\left(\frac{\partial T^{y}}{\partial Z}\right) \\
+\lambda \theta \gamma T^{y}=c Z+\delta\left(T^{y}\right)^{2}
\end{gathered}
$$

The first expression (14a) implies that, due to the inability of tolling $y$, the federal toll will be below its first-best level. To see this, note that the toll on the highway raises traffic through the local town $\left(\frac{\partial T^{y}}{\partial \tau_{x}}>0\right.$, see (9)), the second term on the left-hand side is positive. This immediately implies that

$$
\tau_{x}-\beta_{x}\left(\bar{X}_{O D}-X_{O D}^{y}\right)<0
$$

To interpret the second expression (14b), we first use (5) to rewrite it as

$$
\begin{aligned}
-\left(\tau_{x}-\right. & \left.\beta_{x}\left(\bar{X}_{O D}-X_{O D}^{y}\right)+\left(\beta_{y}+\delta Z\right) T^{y}+\lambda \theta(1-\gamma Z)\right) \frac{\partial X_{O D}^{y}}{\partial Z} \\
- & {\left[\left(\beta_{y}+\delta Z\right) T^{y}+\lambda \theta(1-\gamma Z)\right]\left((1+\rho) \frac{\partial X_{O C}}{\partial Z}\right)+\lambda \theta \gamma T^{y}=c Z+\delta\left(T^{y}\right)^{2} }
\end{aligned}
$$

Straightforward algebra, using (5) and (14a), further shows that

$$
\left(\tau_{x}-\beta_{x}\left(\bar{X}_{O D}-X_{O D}^{y}\right)+\left(\beta_{y}+\delta Z\right)\left(T^{y}\right)+\lambda \theta(1-\gamma Z)\right)>0 .
$$

Using this result, we can finally rewrite first-order condition (14b) as

$$
\{\Omega\}+\lambda \theta \gamma T^{y}=c Z+\delta\left(T^{y}\right)^{2}
$$


where

$$
\begin{aligned}
\{\Omega\}= & -\left(\tau_{x}-\beta_{x}\left(\bar{X}_{O D}-X_{O D}^{y}\right)+\left(\beta_{y}+\delta Z\right) T^{y}+\lambda \theta(1-\gamma Z)\right) \frac{\partial X_{O D}^{y}}{\partial Z} \\
& -\left[\left(\beta_{y}+\delta Z\right) T^{y}+\lambda \theta(1-\gamma Z)\right]\left((1+\rho) \frac{\partial X_{O C}}{\partial Z}\right) \geq 0
\end{aligned}
$$

is necessarily non-negative.

This has two implications. First, comparing (14c) to the first best-rule (13c) implies that, in the absence of a local toll instrument, the second-best rule identifies an extra benefit of traffic calming. It reduces accident and congestion externalities in the local town and it generates higher toll revenues on the main road; these factors more than outweigh the extra cost induced by traffic calming, viz., the increase in congestion on the main road. The extra benefit induces more traffic calming than in the first best. Second, note that for traffic calming measures that do not affect congestion on the local road $y$, such as biking paths or a pedestrian bridge, we have $\delta=0$, so that (7) implies that $\Omega=0$. In these cases, therefore, the second-best rule for traffic calming equals the first-best rule.

We summarize in Proposition 1.

\section{Proposition 1. The first- and second-best solutions}

a. The first-best requires the use of three instruments: a toll on the use of the main road, a toll on the use of the local road, and traffic calming on the local road.

b. The inability to toll the local road implies that the second-best optimum yields a lower toll on the main road and more traffic calming on the local road compared to the first-best.

\section{Vertical competition: tolls, traffic diversion and local traffic calming}

In this section, we study the vertical competition between a higher authority (the 'federal' level), responsible for imposing tolls on $x$, and a local authority that uses local measures to limit local congestion and other external costs imposed upon the local population. What are the implications for local decisions on traffic calming $Z$ when federal policies change? How does the federal government respond to more traffic calming at the local level? How inefficient is the Nash equilibrium that results from the interaction between the two governments?

Note that we focus here on the use of tolls and traffic calming measures such as speed bumps, traffic lights, pedestrian bridges, etc. Formal access restrictions (no through traffic, no 
through traffic for trucks) require a slightly different approach; they are studied in detail in Section 6 below. Moreover, we study the interaction between the two government levels within a Nash equilibrium framework. A Stackelberg setting is less convincing, because the two players would have difficulties to credibly commit to the policies they announce. In Section 4.4 below we do briefly discuss leader-follower models as special cases.

\subsection{The local government's problem: how much traffic calming?}

Let a toll $\tau_{x}$ be in place, imposed by the federal authority (note that the toll can of course be zero). The local level controls investment in traffic calming on $y$. The local government solves (see $11 \mathrm{~b}$ ):

$$
\operatorname{Max}_{Z} \frac{\rho}{1+\rho} \int_{0}^{(1+\rho) X_{O C}} P(q) d q-G C_{y}\left(Y_{L C}+\bar{Y}_{L D}\right)-0.5 c Z^{2}-(\lambda \theta(1-\gamma Z))\left(T^{y}\right)
$$

The first-order condition for the optimal choice of $Z$ can be written as:

$$
-\left[\left(\beta_{y}+\delta Z\right)\left(Y_{L C}+\bar{Y}_{L D}\right)+\lambda \theta(1-\gamma Z)\right]\left(\frac{\partial T^{y}}{\partial Z}\right)+\lambda \theta \gamma T^{y}=c Z+\delta T^{y}\left(Y_{L C}+\bar{Y}_{L D}\right)
$$

Compared to the first-best rule (given by $\lambda \theta \gamma T^{y}=c Z+\delta\left(T^{y}\right)^{2}$, see (13c) above), we note two main differences. First, the left-hand side (15) indicates that the local government enjoys an extra benefit: more traffic calming negatively affects the traffic flow through the municipality, reducing local accident risks and local congestion. Second, the right-hand side reflects the fact that the marginal social cost of investing in $Z$ is lower because the local authority only considers the congestion effect of the traffic calming measures for traffic demand by the local population. On both accounts one expects the local authorities to overinvest in traffic calming compared to the first-best.

Demands $X_{O D}^{y}, X_{O C}, Y_{L C}$ all depend on $\tau_{x}$ and on $Z$, so that we can write (15) as an implicit function $\phi\left(Z, \tau_{x}\right)=0$. This implicitly defines the reaction function $Z^{r}\left(\tau_{x}\right)$ of the local government, describing how the federal toll affects the choice of traffic calming. Using the implicit function theorem we then derive the effect of a higher toll on road section $x$ on the optimal traffic calming investment by the local government as: 


$$
\frac{d Z^{r}\left(\tau_{x}\right)}{d \tau_{x}}=-\frac{\frac{\partial \phi\left(Z, \tau_{x}\right)}{\partial \tau_{x}}}{\frac{\partial \phi\left(Z, \tau_{x}\right)}{\partial Z}}
$$

The denominator is negative by the second-order condition of the local government's optimization problem. In Appendix 1 we show that the numerator is unambiguously positive. Expression (16) therefore implies that the local government will respond to a toll increase on the main road by raising traffic calming:

$$
\frac{d Z^{r}\left(\tau_{x}\right)}{d \tau_{x}}>0
$$

This seems plausible: the higher toll diverts traffic from the main road through the local town, generating extra congestion and other local externalities for the local population. To counteract this, the local government raises traffic calming on the local road.

The implicit function theorem also allows us to investigate the effect of some relevant parameters of the problem on traffic calming. We find that an increase in $\gamma$ (traffic calming is more effective in reducing external accident costs) increases traffic calming; the same holds when accident costs are higher (an increase in $\lambda$ ). The effect of a higher $\delta$ (the degree to which traffic calming raises generalized cost) is ambiguous: at given traffic flows it certainly reduces traffic calming, but it also affects the demand for trips.

\subsection{The effect of traffic calming on the federal toll}

Assuming the local authority has traffic calming measures in place, the optimal federal toll maximizes its welfare function (see (10a)) with respect to the toll. Of course, as it considers the welfare of all road users and it takes account of all externalities, the first-order condition is the same as (14a), the condition for the second-best optimal toll. We rewrite is as follows:

$$
-\left(\tau_{x}-\beta_{x}\left(\bar{X}_{O D}-X_{O D}^{y}\right)\right) \frac{\partial X_{O D}^{y}}{\partial \tau_{x}}=\left\{\left[\left(\beta_{y}+\delta Z\right)\left(T^{y}\right)+\lambda \theta(1-\gamma Z)\right]\left[\frac{\partial T^{y}}{\partial \tau_{x}}\right]\right\}
$$

The right-hand side is positive, confirming that the federal toll will be below marginal external cost (see the left-hand side). The toll raises traffic on the local road, which the federal government does not control. A lower toll is therefore set because it limits traffic diverted 
towards the local road. Note that if congestion on $x$ is not a major problem, the optimal toll might easily be zero, and we have a corner solution.

Suppose congestion on the main road is sufficiently relevant so that we have an internal optimum. Rewrite (17) as an implicit function $\varphi\left(Z, \tau_{x}\right)=0$, implicitly defining the federal government's reaction function $\tau_{x}^{r}(Z)$. The effect of traffic calming by the local community on the federal toll is:

$$
\frac{d \tau_{x}^{r}(Z)}{d Z}=-\frac{\frac{\partial \varphi\left(Z, \tau_{x}\right)}{\partial Z}}{\frac{\partial \varphi\left(Z, \tau_{x}\right)}{\partial \tau_{x}}} .
$$

In Appendix 2 we show that this expression is positive; we have:

$$
\frac{d \tau_{x}^{r}(Z)}{d Z}>0
$$

More traffic calming by the local authorities leads the federal government to increase the toll. Traffic calming shifts demand back to the main road, and the federal government responds by raising the toll.

We further find that an increase in $\gamma$ (more effective traffic calming) increases the toll at a given level of traffic calming. Higher accident costs (an increase in $\lambda$ ) reduce the toll. The effect of a higher $\delta$ is again ambiguous.

\subsection{The Nash equilibrium}

In this section we show that governmental competition produces a Nash equilibrium with a toll that is too high and too much traffic calming compared to the second best optimum. To see this, we proceed as follows.

First, rewriting (14b), the effect of $Z$ on total federal welfare $W(f)$ is:

$$
\begin{aligned}
\frac{\partial W(f)}{\partial Z}=- & \left(\tau_{x}-\beta_{x}\left(\bar{X}_{O D}-X_{O D}^{y}\right)\right) \frac{\partial X_{O D}^{y}}{\partial Z} \\
- & {\left[\left(\beta_{y}+\delta Z\right) T^{y}+\lambda \theta(1-\gamma Z)\right]\left(\frac{\partial T^{y}}{\partial Z}\right)+\lambda \theta \gamma T^{y}-c Z-\delta\left(T^{y}\right)^{2} }
\end{aligned}
$$

Then note that the optimal Nash equilibrium value $Z^{N E}$ solves the first-order condition for the local authority's choice of traffic calming, as given by (15) above; it therefore satisfies: 


$$
\begin{gathered}
-\left[\left(\beta_{y}+\delta Z^{N E}\right)\left(Y_{L C}+\bar{Y}_{L D}\right)+\lambda \theta\left(1-\gamma Z^{N E}\right)\right]\left(\frac{\partial T^{y}}{\partial Z}\right)+\lambda \theta \gamma T^{y} \\
=c Z^{N E}+\delta T^{y}\left(Y_{L C}+\bar{Y}_{L D}\right)
\end{gathered}
$$

where all traffic volumes and derivatives are evaluated at the optimal Nash equilibrium value $Z^{N E}$. Combining (19) and (20) we easily show, using the definition of $T^{y}$ given in (5), that

$$
\begin{aligned}
\left.\frac{\partial W(f)}{\partial Z}\right|_{Z=Z^{N E}}=-( & \left.\tau_{x}-\beta_{x}\left(\bar{X}_{O D}-X_{O D}^{y}\right)\right) \frac{\partial X_{O D}^{y}}{\partial Z} \\
- & {\left[\left(\beta_{y}+\delta Z^{N E}\right) \frac{\partial T^{y}}{\partial Z}+\delta T^{y}\right]\left(X_{O D}^{y}+X_{O C}\right) }
\end{aligned}
$$

This expression has two implications. First, consider traffic calming measures that do not slow down traffic on the municipal road $y$. In that case $\delta=0$. This implies that traffic calming $Z$ does not affect traffic levels: by (7) we have $\frac{\partial X_{O D}^{y}}{\partial Z}=\frac{\partial T^{y}}{\partial Z}=0$. It then immediately follows that (21) equals zero. Conditional on a given toll, the Nash equilibrium traffic calming level is therefore second-best socially optimal. Knowing that the toll rule -- describing the behavior of the federal government -- is the same as the second-best optimal rule, this basically means that the Nash equilibrium coincides with the second-best social optimum.

Second, in all other cases, the right-hand side of (21) is necessarily negative. The first term is negative, because traffic calming $Z$ reduces diverted traffic and the toll is below external congestion cost. Moreover, the second term is negative as well: starting from the definition (3) of the generalized cost of road $y$, and using (5), (7) and (8), we easily show:

$$
\left(\beta_{y}+\delta \mathrm{z}\right) \frac{\partial T^{y}}{\partial Z}+\delta T^{y}=\frac{\partial G C_{y}}{\partial Z}=\frac{\delta(1+\rho)^{2}}{\Delta^{2}} b \beta_{x}(\mathrm{H})>0
$$

Note that this expression just captures the positive effect of traffic calming on the generalized cost via $y$.

Combining these results we have

$$
\left.\frac{\partial W(f)}{\partial Z}\right|_{Z=Z^{N E}}<0 \text {. }
$$

Evaluated at the Nash equilibrium, federal welfare would therefore decline if more was invested in traffic calming. Differently stated, at the Nash equilibrium the local level overinvests relative to the second-best optimum. Graphically (see Figure 2), the second best social optimum is to the left of the local government's reaction function $Z^{r}\left(\tau_{x}\right)$. Moreover, as the federal government's reaction function $\tau_{x}^{r}(Z)$ is positively sloped, the second-best optimum implies 
both a lower toll and less traffic calming than the Nash equilibrium. The competition between the local and federal level therefore leads to too high tolls and too much local traffic calming.

The Nash equilibrium and the second best social optimum are illustrated in Figure 2. The second best optimum is located on the reaction function of the federal government's toll as function of the level of local traffic calming. The Nash equilibrium therefore involves a higher toll and a higher level of traffic calming than the second best optimum. It also implies higher toll and traffic calming levels than when the two authorities would only use one instrument.

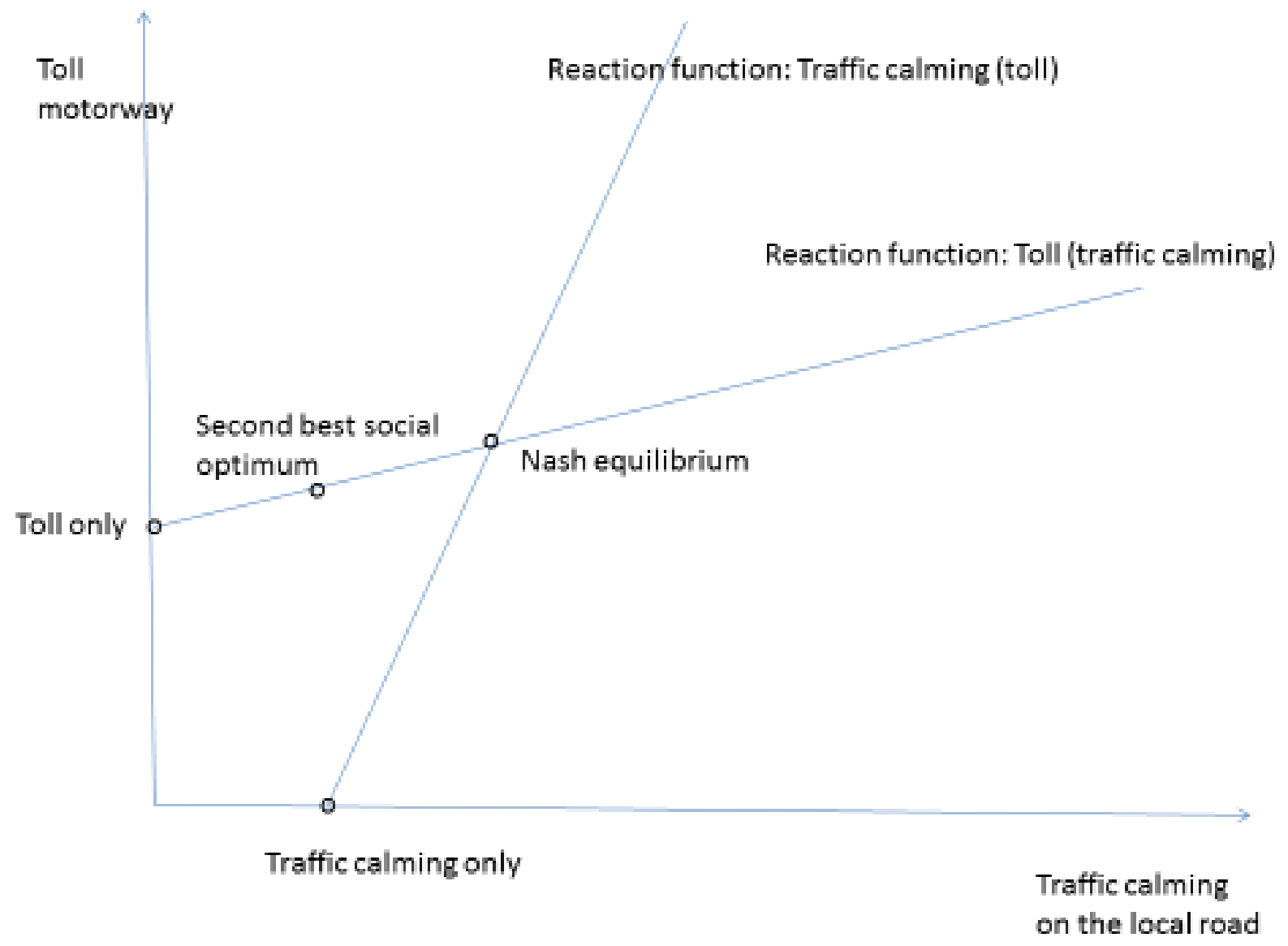

Figure 2. Illustrating the Nash equilibrium and the second-best social optimum

We summarize our findings in the following proposition.

Proposition 2. Suppose the federal government controls a toll on the main road, the local government controls local traffic calming instruments.

a. A higher toll on the main road raises traffic calming by the local authority.

b. More traffic calming in the local community raises the optimal federal toll. 
c. For traffic calming measures that raise the generalized cost of traffic on the local road (speed bumps, traffic lights), the Nash equilibrium implies too high tolls on the main road and too much traffic calming at the local level compared to the second-best optimum.

d. For traffic calming measures that do not raise the generalized cost of using the local road (pedestrian bridges, biking paths, low emission zones), the Nash equilibrium is second-best socially optimal.

\subsection{A leader-follower setting}

In this subsection, we briefly consider a leader-follower setting. Of course, one-shot leader-follower models may suffer from time inconsistencies, unless the leader can commit that the decision taken will not be adapted after observing the follower's response. In this sense, Nash equilibrium is preferable as a description of behavioral outcomes ${ }^{7}$. For completeness' sake, we do briefly look at Stackelberg leader-follower models.

First, suppose that the local government moves first. In Appendix 3 we show that this setting leads to both less traffic calming and a lower toll as compared to the Nash equilibrium.

Second, it is even easier to see what happens when the federal government acts as the leader. As the federal government maximizes total welfare, it can never do worse than the Nash equilibrium because the latter is one of the outcomes it can actually choose (both the Nash and the leader-follower equilibrium are on the local government's reaction function). It is again easy to show that one obtains an equilibrium with a lower toll and a lower level of traffic calming compared to the Nash outcome.

The leader-follower equilibria are illustrated in Figure 3.

\footnotetext{
${ }^{7}$ Commitment is problematic, both for the federal and the local government, but probably more for the federal than the local government. Consider the federal problem. Investing in the technology required to implement tolls on the main road may signal that the federal government is highly committed to imposing tolls, but it is much harder to commit to the toll level: the investment is a sunk cost, and toll levels can easily be changed after observing the investment in traffic calming by the local government. For the local government, commitment is more credible. Eliminating speed bumps or pedestrian bridges may be too costly to consider, and budgetary constraints may make additional investments problematic.
} 


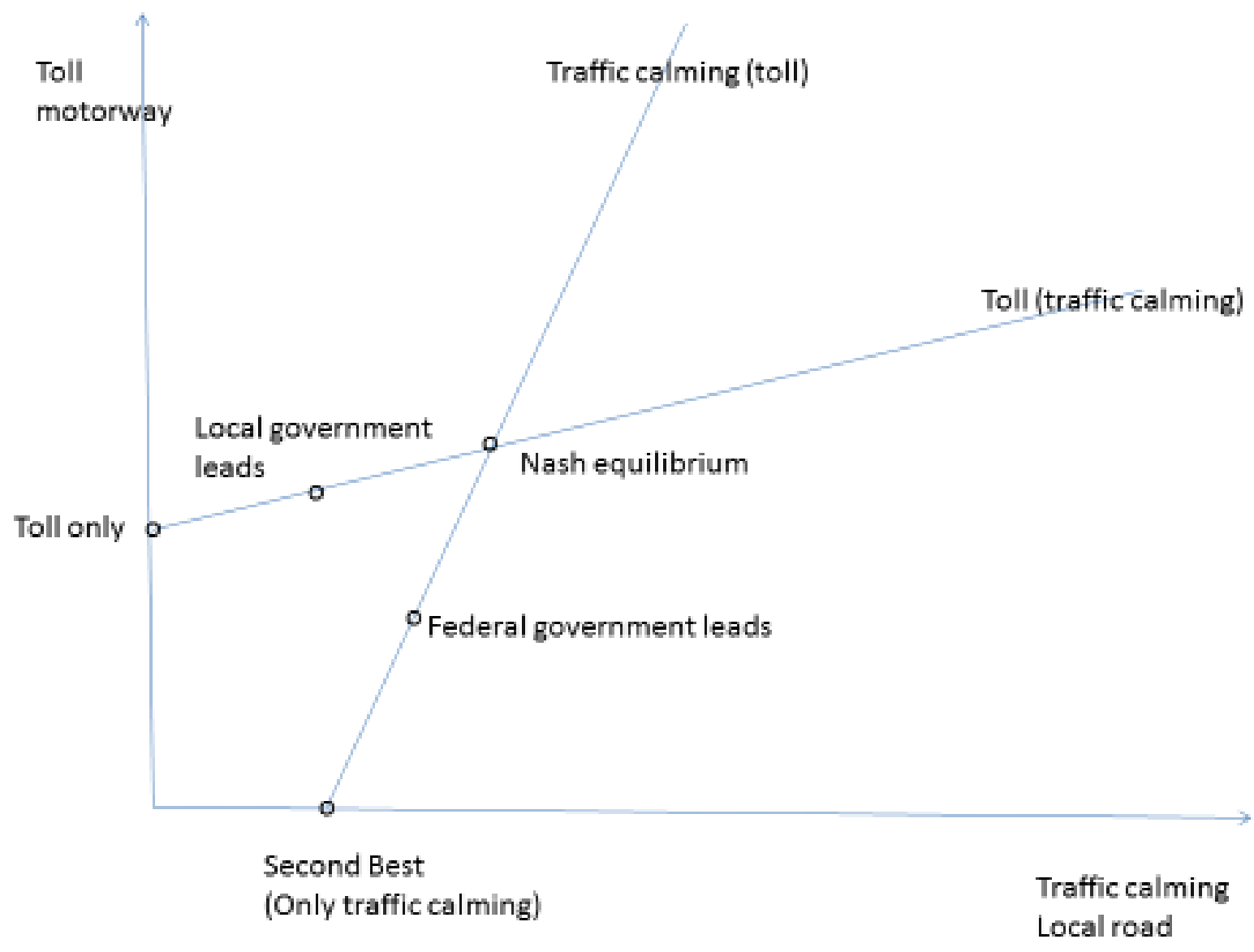

Figure 3. Nash equilibrium and leader-follower outcomes

\section{On the allocation of authority}

The previous sections showed that the use of tolls by the federal government and traffic calming by the local government leads to undesirable outcomes. The inefficiency of the vertical competition between the two governments raises two other issues, both related to the allocation of authority over the policy instruments.

First, can an outcome in which one of the instruments is not used at all achieve higher welfare than the Nash equilibrium? For example, given that traffic calming is widely used by local authorities, is it a good idea for the federal government to implement a federal toll on the main road, or is it better not to do so? The answer is ambiguous in general: the toll will shift traffic from the main road to the local road; this reduces congestion on the main road, but it increases accident and congestion externalities in the local community. Alternatively, suppose the federal government implements tolling on the main road, is it then still a good idea to give 
the local government the authority to decide on local traffic calming measures? Again, the answer is not a priori clear.

A second important question is the following: are there institutional arrangements between the two government levels that yield higher welfare than the inefficient Nash equilibrium. If so, can they attain or approximate the second-best optimum?

\subsection{Given a federal toll, is local control of traffic calming welfare-improving?}

Suppose the federal government introduced a toll on the main road. The question is then whether allowing the local government to decide on traffic calming measures is a good idea? To find out we compare federal welfare (i) under a federal toll only, and (ii) at the Nash equilibrium. In terms of Figure 2, we compare federal welfare at the intersection of the reaction functions (the Nash equilibrium) and at the intersection of the federal government's toll reaction function with the vertical axis (implying no traffic calming).

When the federal level imposes a toll only, its welfare - adapting (10b) for the absence of traffic calming - can be written as:

$$
W^{0}(f)=\frac{b}{2}(1+\rho)^{2}\left(X_{O C}^{0}\right)^{2}-G C_{x}^{0}\left(\bar{X}_{O D}+\bar{Y}_{L D}\right)+\tau_{x}^{0}\left(\bar{X}_{O D}-X_{O D}^{y, 0}\right)-\lambda \theta T^{y, 0}
$$

The superscript ' 0 ' refers to the case 'toll only'. Federal welfare at the Nash equilibrium can similarly be written as (demand levels and costs are indexed ' $N E$ '):

$$
\begin{aligned}
W^{N E}(f)=\frac{b}{2}(1+\rho)^{2}\left(X_{O C}^{N E}\right)^{2}-G C_{x}^{N E}\left(\bar{X}_{O D}+\bar{Y}_{L D}\right)+\tau_{x}^{N E}\left(\bar{X}_{O D}-X_{O D}^{y, N E}\right) \\
-0.5 c\left(Z^{N E}\right)^{2}-\lambda \theta\left(1-\gamma Z^{N E}\right) T^{y, N E}
\end{aligned}
$$

Subtracting (23) from (24), using the definition of the generalized costs, and rearranging the result we can write the difference in welfare levels as follows:

$$
\begin{aligned}
W^{N E}(f)-W^{0}(f)= & \frac{b}{2}(1+\rho)^{2}\left[\left(X_{O C}^{N E}\right)^{2}-\left(X_{O C}^{0}\right)^{2}\right] \\
& -\left(G C_{x}^{N E}-G C_{x}^{0}\right) \bar{Y}_{L D}-0.5 C\left(Z^{N E}\right)^{2} \\
& -\lambda \theta\left(T^{y, N E}-T^{y, 0}\right)-\left(\tau_{x}^{N E} X_{O D}^{y, N E}-\tau_{x}^{0} X_{O D}^{y, 0}\right) \\
& +\beta_{x}\left(X_{O D}^{y, N E}-X_{O D}^{y, 0}\right) \bar{X}_{O D}+\lambda \theta \gamma Z^{N E} T^{y, N E}
\end{aligned}
$$

To interpret this expression, note that $\tau_{x}^{N E}>\tau_{x}^{0}$ (see Figures 2 and 3). Moreover, in Appendix 4 we formally show the following inequalities:

$$
G C^{N E}>G C^{0} ; X_{O C}^{N E}<X_{O C}^{0} ; \quad T^{y, N E}>T^{y, 0} ; \quad X_{O D}^{y, N E}>X_{O D}^{y, 0} .
$$

The results of (26) are intuitive. The generalized cost at the Nash equilibrium exceeds the one when only a (lower) toll is implemented. This also leads to lower price-sensitive demand: 
$X_{O C}^{N E}<X_{O C}^{0}$. The combination of more traffic calming and a higher toll at the Nash equilibrium leads to more traffic diverted from the main road to the local road; $X_{O D}^{y}$ is therefore higher at the Nash equilibrium. This implies that the effect of the higher toll and the reduction in pricesensitive demand on $y$ dominates the effect of more traffic calming. Finally, because of the increase in diverted traffic, total demand $T^{y}$ using route $y$ is increasing.

Using (26) in (25) shows that all terms on the first three lines of the welfare difference $W^{N E}(f)-W^{0}(f)$ are unambiguously negative. Compared to the use of tolls only, the various terms capture the loss in consumer surplus at the Nash equilibrium, the increase in generalized costs for local commuting traffic, the cost of the traffic calming measures, the increase in accident costs and the loss in toll revenues on diverted traffic.

The two terms on the last line are positive. The term $\left(\beta_{x}\left(X_{O D}^{y, N E}-X_{O D}^{y, 0}\right) \bar{X}_{O D}\right)$ reflects the fact that there is more traffic diversion to the local road at the Nash equilibrium, saving on external congestion costs on the main road. The final term $\left(\lambda \theta \gamma Z^{N E} T^{y, N E}\right)$ captures the savings in external accident costs due to the use of traffic calming measures. The size of this term crucially depends on how effective traffic calming is in reducing local external costs (i.e., on the value of $\gamma$ ).

In sum, expression (25) tells us that, if the federal government uses a toll on the main road, it is not necessarily a good idea to grant authority over traffic calming measures to the local authority. If the main road is not very congestible (i.e., if $\beta_{x}$ is small) and traffic calming is not highly effective in reducing accident externalities ( $\gamma$ is small) then the use of traffic calming measures by the local authorities is certainly reducing overall welfare. Giving authority to use traffic calming by the local government may increase welfare only if the main road is highly congestible, and traffic calming is very effective in reducing traffic-related nuisances for the local population. Under those conditions the last two terms in (25) may dominate.

\subsection{Given traffic calming, is a federal toll on the main road welfare-improving?}

In this section we ask the question whether, given the use of traffic calming instruments by local governments, introducing tolling on the main road is in fact welfare-improving. The methodology is the same as in section 5.1. We compare the Nash equilibrium (where both instruments are used) with the outcome when the only instrument used is traffic calming, as decided by the local authority. 
When there is no toll and only $Z$ is implemented by the local level, federal welfare can be written as:

$$
W^{1}(f)=\frac{b}{2}(1+\rho)^{2}\left(X_{O C}^{1}\right)^{2}-G C_{x}^{1}\left(\bar{X}_{O D}+\bar{Y}_{L D}\right)-0.5 c\left(Z^{1}\right)^{2}-\lambda \theta\left(1-\gamma Z^{1}\right) T^{y, 1}
$$

The superscript ' 1 ' refers to the case ' $Z$ only'. The welfare difference with the Nash equilibrium is, using (24) and (27):

$$
\begin{aligned}
W^{N E}(f)-W^{1}(f)= & \frac{b}{2}(1+\rho)^{2}\left[\left(X_{O C}^{N E}\right)^{2}-\left(X_{O C}^{1}\right)^{2}\right] \\
& -\left(G C_{x}^{N E}-G C_{x}^{1}\right) \bar{Y}_{L D}-0.5 C\left[\left(Z^{N E}\right)^{2}-\left(Z^{1}\right)^{2}\right] \\
& -\lambda \theta\left(T^{y, N E}-T^{y, 1}\right)-\tau_{x}^{N E} X_{O D}^{y, N E} \\
& +\beta_{x}\left(X_{O D}^{y, N E}-X_{O D}^{y, 1}\right) \bar{X}_{O D}+\lambda \theta \gamma\left(T^{y, N E} Z^{N E}-T^{y, 1} Z^{1}\right)
\end{aligned}
$$

Note that $Z^{N E}>Z^{1}$, see Figures 2 and 3. Using the results shown in Appendix 4, we further have:

$$
G C^{N E}>G C^{1}, X_{O C}^{N E}<X_{O C}^{1}, T^{y, N E}>T^{y, 1} ; \quad X_{O D}^{y, N E}>X_{O D}^{y, 1} .
$$

Using (29) in (28), it follows that - assuming local authorities implement traffic calming measures -- imposing tolls on the main road is not necessarily increasing federal welfare. All terms on the first three lines in (28) are unambiguously negative, but the last two terms are necessarily positive. Interpretation is quite similar to section 5.1. If the first four terms dominate, competition between the two governments implies that introducing a toll on the main road will reduce welfare. As suggested by (28) this will be the case, unless the main road is highly congestible and traffic calming is very effective. In that case, the savings in congestion costs on the main road are very high. Moreover, the Nash equilibrium implies higher traffic calming than when no toll where imposed; this further raise welfare.

We summarize the results of sections 5.1 and 5.2 in the following proposition.

\section{Proposition 3. The allocation of decision authority.}

a. If the local authority uses local traffic calming measures, imposing a federal toll on the main road can be welfare-reducing. It will only increase federal welfare if the main road suffers from very high congestion and traffic calming is quite effective in reducing local accident costs.

b. If a federal toll were in place on the main road, then granting authority to the local community over traffic calming measures may be unjustified, except when doing so is highly effective in reducing local external costs imposed on the local community. 


\subsection{Institutional arrangements and the allocation of authority over instruments}

In this subsection, we ask whether the inefficiencies due to competition between governments can be limited by simple institutional arrangements. More in particular, we show that bargaining over tolls and traffic calming measures by two public agencies with welldefined objectives may be a highly efficient arrangement.

Before doing so, let us first point out institutional arrangements that may seem desirable but that do not necessarily help in reducing the inefficiency. Many federal governments provide conditional grants to local authorities to co-finance local traffic calming measures. This may be justified in the sense that local governments have limited taxing capacity, but it is easy to show that they may aggravate the inefficiency due to vertical tax competition. The reason is that the implied subsidies raise the demand for traffic calming by the local authorities and, given the upward sloping reaction function of the federal government, they increase the federal toll above the Nash equilibrium toll in the absence of subsidies. Second, for similar reasons toll revenue sharing by the federal government may not help.

Consider instead the following arrangements. Let the government define a hierarchy of roads (main, local) and set up two public agencies, one for the local road and one for the motorway. Each agency is responsible for the welfare of road users of the roads they control. Of course, there are conflicting interests between the two agencies. Assume, therefore, that a formalized bargaining structure is imposed on the decision-making process: decisions on both tolling and traffic calming are made by negotiation between the agencies.

Specifically, then, suppose the agency responsible for the main road cares for the net consumer surplus of its users and for the toll revenues. Its preferred toll is the solution of:

$$
\operatorname{Max}_{\tau_{x}} \quad W^{x}=\int_{0}^{\bar{X}_{O D}-X_{O D}^{y}} P(q) d q-G C_{x}\left(\bar{X}_{O D}-X_{O D}^{y}\right)+\tau_{x}\left(\bar{X}_{O D}-X_{O D}^{y}\right)
$$

It easily follows, using simple algebra, that they would set the toll according to the first-best rule

$$
\tau_{x}=\beta_{x}\left(\bar{X}_{O D}-X_{O D}^{y}\right) .
$$

Similarly, let the agency responsible for the local road system be concerned about the net surplus of all users, the cost of traffic calming and the local accident costs and other nuisances. If it could independently set the level of traffic calming, it would set $Z$ as the solution of:

$$
\underset{Z}{\operatorname{Max}} \quad W^{y}=\int_{0}^{T^{y}} P(q) d q-G C_{y}\left(T^{y}\right)-0.5 c Z^{2}-(\lambda \theta(1-\gamma Z))\left(T^{y}\right)
$$


This gives the first-order condition:

$$
-\left(T^{y}\right)\left[\left(\beta_{y}+\delta Z\right)\left(T^{y}\right)+\lambda \theta(1-\gamma Z)\right]\left(\frac{\partial T^{y}}{\partial Z}\right)+\lambda \theta \gamma T^{y}=c Z+\delta\left(T^{y}\right)^{2}
$$

The level of traffic calming will be inefficiently high compared to the first-best.

Now impose a bargaining process on the two agencies. Assuming Nash bargaining with equal bargaining power, tolls and traffic calming levels will then be the solution of:

$$
\begin{gathered}
\operatorname{Max}_{\tau_{x}, Z} W^{x}+W^{y}=\int_{0}^{\bar{X}_{O D}-X_{O D}^{y}} P(q) d q+\int_{0}^{T^{y}} P(s) d s-G C_{x}\left(\bar{X}_{O D}-X_{O D}^{y}\right)-G C_{y}\left(T^{y}\right) \\
+\tau_{x}\left(\bar{X}_{O D}-X_{O D}^{y}\right)-0.5 c Z^{2}-(\lambda \theta(1-\gamma Z))\left(T^{y}\right)
\end{gathered}
$$

Using the definition of $T^{y}$ and rearranging, it easily follows that this boils down to the federal second-best optimization problem considered before:

$$
\begin{gathered}
\operatorname{Max}_{\tau_{x}, Z} W^{x}+W^{y}=\int_{0}^{(1+\rho) X_{O C}} P(q) d q-G C_{x}\left(\bar{X}_{O D}-X_{O D}^{y}\right)-G C_{y}\left(T^{y}\right)+\tau_{x}\left(\bar{X}_{O D}-X_{O D}^{y}\right) \\
-0.5 c Z^{2}-(\lambda \theta(1-\gamma Z))\left(T^{y}\right)
\end{gathered}
$$

Consequently, the outlined procedure would, at least in theory, reproduce the second-best social optimum.

Of course, caution is needed when interpreting this finding. It will not hold if the agencies pursue different objectives than those postulated; moreover, bargaining power may differ between the two agencies. However, do note that in several countries the type of road hierarchy suggested here does exist (including Belgium, the Netherlands, Germany, etc.), whereby decisions over local traffic calming measures (for example, placing traffic lights to access the local road) are taken after intense negotiations. ${ }^{8}$

\section{Proposition 4. Setting up a hierarchy of roads and bargaining between the agencies responsible for each type of road can induce the second-best social optimum.}

\section{Formal access restrictions}

So far we have focused on traffic calming measures such as pedestrian bridges, speed bumps and traffic lights; such measures reduce local nuisances and accident risks, and a subset of these measures slow down traffic on the local road. However, as mentioned in the introduction, modern technology allows local authorities to use more drastic measures. In this

\footnotetext{
${ }^{8}$ Tolling is not yet very common.
} 
section, we study the effect of formally restricting access to the local municipal road $y$ for through traffic. We first consider access restrictions that apply to all through traffic. We then extend the model to study such a ban only applying for trucks.

\subsection{No through traffic allowed on the local road}

To emphasize the role of access restrictions, we assume there is no toll on the main road; we briefly discuss below how the results change when a federal toll is in place. Moreover, the local authority uses no other traffic calming measures apart from not allowing through traffic. In other words, we assume in this section that $\tau_{x}=0 ; Z=0$. Importantly, we ignore implementation costs (the costs associated with installing the technology) throughout this section.

Not allowing through traffic to pass via $y$ implies the restriction that no diverted traffic is allowed, i.e., $X_{O D}^{y}=0$. This has two implications. First, the generalized costs are now formulated as

$$
\begin{aligned}
& G C_{x}=\alpha_{x}+\beta_{x} \bar{X}_{O D} \\
& G C_{y}=\alpha_{y}+\beta_{y}\left((1+\rho) X_{O C}+\bar{Y}_{L D}\right)
\end{aligned}
$$

Second, the Wardrop condition that equalizes generalized costs on roads $x$ and $y$ does not apply. We find the equilibrium traffic flow $X_{O C}$ originating in $O$ and having the local community as final destination by equating the generalized price and the generalized cost of using road $y$ :

$$
a-b(1+\rho) X_{O C}=\alpha_{y}+\beta_{y}\left((1+\rho) X_{O C}+\bar{Y}_{L D}\right)
$$

This immediately yields:

$$
X_{O C}=\frac{a-\alpha_{y}-\beta_{y} \bar{Y}_{L D}}{(1+\rho)\left(b+\beta_{y}\right)} .
$$

We consecutively study how federal and local welfare are affected by the ban on through traffic.

\section{The federal point of view}

Does federal welfare increase when through traffic is prohibited? The restriction affects consumer surplus of non-commuting traffic, it affects congestion on both the main and the local road, and it affects external accident costs. 
Given the restriction of zero through traffic, federal welfare is given by

$$
\int_{0}^{(1+\rho) X_{O C}} P(z) d z-G C_{x} \bar{X}_{O D}-G C_{y}\left((1+\rho) X_{O C}+\bar{Y}_{L D}\right)-\lambda \theta\left((1+\rho) X_{O C}+\bar{Y}_{L D}\right)
$$

In what follows, we use superscripts ' $R$ ' to denote the restriction of zero through traffic. Federal welfare can then be rewritten after simple algebra:

$$
\begin{gathered}
W^{R}(f)=\frac{b}{2}\left[(1+\rho) X_{O C}^{R}\right]^{2}-\left[\alpha_{x}+\beta_{x} \bar{X}_{O D}\right] \bar{X}_{O D}-\left[\alpha_{y}+\beta_{y}\left((1+\rho) X_{O C}^{R}+\bar{Y}_{L D}\right)\right] \bar{Y}_{L D} \\
-\lambda \theta\left((1+\rho) X_{O C}^{R}+\bar{Y}_{L D}\right)
\end{gathered}
$$

We are interested in comparing welfare with and without the access restrictions. Unrestricted welfare (we use superscripts ' $U$ ') was given by (10b) above. Imposing a zero toll and the absence of other traffic calming measures $Z$, it can be written as:

$$
W^{U}(f)=\frac{b}{2}\left[(1+\rho) X_{O C}^{U}\right]^{2}-\left[\alpha_{x}+\beta_{x}\left(\bar{X}_{O D}-X_{O D}^{y, U}\right)\right]\left(\bar{X}_{O D}+\bar{Y}_{L D}\right)-(\lambda \theta)\left(T^{y, U}\right)
$$

We can write the federal welfare difference after straightforward algebra as:

$$
\begin{aligned}
& W^{R}(f)-W^{U}(f)= \frac{b}{2}(1+\rho)^{2}\left[\left(X_{O C}^{R}\right)^{2}-\left(X_{O C}^{U}\right)^{2}\right]-\beta_{x} X_{O D}^{y, U} \bar{X}_{O D} \\
&+\left\{\alpha_{x}+\beta_{x}\left(\bar{X}_{O D}-X_{O D}^{y, U}\right)-\left[\alpha_{y}+\beta_{y}\left((1+\rho) X_{O C}^{R}+\bar{Y}_{L D}\right)\right]\right\} \bar{Y}_{L D} \\
&+\lambda \theta\left[X_{O D}^{y, U}+(1+\rho)\left(X_{O C}^{U}-X_{O C}^{R}\right)\right]
\end{aligned}
$$

Note that the Wardrop equilibrium condition holds in the unrestricted situation

$$
\alpha_{x}+\beta_{x}\left(\bar{X}_{O D}-X_{O D}^{y, U}\right)=\alpha_{y}+\beta_{y}\left(X_{O D}^{y, U}+(1+\rho) X_{O C}^{U}+\bar{Y}_{L D}\right)
$$

Use this expression and rearrange the welfare difference (31) to find:

$$
\begin{aligned}
W^{R}(f)-W^{U}(f)= & \frac{b}{2}(1+\rho)^{2}\left[\left(X_{O C}^{R}\right)^{2}-\left(X_{O C}^{U}\right)^{2}\right] \\
& -\beta_{x} X_{O D}^{y, U} \bar{X}_{O D} \\
& +\left(\beta_{y} \bar{Y}_{L D}+\lambda \theta\right)\left[X_{O D}^{y, U}+(1+\rho)\left(X_{O C}^{U}-X_{O C}^{R}\right)\right]
\end{aligned}
$$

To interpret this expression, we first use expressions (6) and (30), giving unrestricted and restricted price sensitive demand, respectively. ${ }^{9}$ Algebra shows the following:

$$
\begin{aligned}
& X_{O C}^{R}>X_{O C}^{U} \\
& X_{O D}^{y, U}+(1+\rho)\left(X_{O C}^{U}-X_{O C}^{R}\right)>0
\end{aligned}
$$

These findings are intuitive. The first inequality says that non-commuting demand by outsiders from $O$ that have the local community as final destination rises when through traffic is no longer

\footnotetext{
${ }^{9}$ Of course, we impose $\tau_{x}=Z=0$ in (6) to reflect our assumptions of a zero toll and no traffic calming except access restrictions.
} 
allowed. The second inequality means that total demand passing via the local road $y$ will decline when through traffic is no longer allowed: the reduction in through traffic to zero is larger than the induced extra non-commuting demand.

Then interpret the above welfare difference (32). The first term captures the surplus increase for non-commuting traffic; it is positive. The second term reflects the fact that restricting access raises congestion on route $x$; it is negative. The third term is positive. It gives the reduction in congestion and local external costs when closing the road for through traffic.

It follows that restricting access may increase or reduce federal welfare. If congestion on the main road is severe (the second term in (32) is large in absolute value) and external costs of passing through the local community are small (the third term is small), restricting access is reducing welfare. If congestion on the main road is not dramatic but local nuisances in the municipality are important, the access restriction improves federal welfare.

\section{The local viewpoint}

Compare welfare with and without access restriction from the viewpoint of the local authority. Without the restriction (superscript ' $U$ ') we have

$$
W^{U}(l)=\frac{b}{2} \frac{1+\rho}{\rho}\left(Y_{L C}^{U}\right)^{2}-G C_{y}^{U}\left(\bar{Y}_{L D}\right)-\lambda \theta\left(X_{O D}^{y, U}+(1+\rho) X_{O C}^{U}+\bar{Y}_{L D}\right)
$$

where $G C_{y}^{U}=\alpha_{y}+\beta_{y}\left(X_{O D}^{y, U}+(1+\rho) X_{O C}^{U}+\bar{Y}_{L D}\right)$. When the access restriction on through traffic is imposed (superscript ' $R$ '), welfare becomes

$$
W^{R}(l)=\left(\frac{1+\rho}{\rho}\right) \frac{b}{2}\left(Y_{L C}^{R}\right)^{2}-G C_{y}\left(\bar{Y}_{L D}\right)-\lambda \theta\left((1+\rho) X_{O C}^{R}+\bar{Y}_{L D}\right)
$$

and $G C_{y}=\alpha_{y}+\beta_{y}\left((1+\rho) X_{O C}^{R}+\bar{Y}_{L D}\right)$.

Comparing local welfare without and with the restriction, we find:

$$
\begin{aligned}
W^{R}(l)-W^{U}(l)= & \left(\frac{1+\rho}{\rho}\right) \frac{b}{2}\left[\left(Y_{L C}^{R}\right)^{2}-\left(Y_{L C}^{U}\right)^{2}\right] \\
& +\left(\beta_{y} \bar{Y}_{L D}+\lambda \theta\right)\left[X_{O D}^{y, U}+(1+\rho)\left(X_{O C}^{U}-X_{O C}^{R}\right)\right]
\end{aligned}
$$

It follows from (33) and $Y_{L C}=\rho X_{O C}$ that expression (34) is unambiguously positive. The local authority will always close the road for through traffic: it ignores the fact that doing so raises congestion on the main road $x$.

Finally, note that introducing a federal toll on the main road would only reinforce the local government's incentive to close the local road for through traffic. The toll would imply 
more diverted traffic from the main road to the local community, strengthening the incentive for the local authority to close the road for through traffic.

\section{Proposition 5: Restricting access to through traffic}

a. From a global welfare perspective it is optimal to keep the local road open for through traffic if congestion on the main road is severe and traffic nuisances imposed on the local population are limited.

b. Unless implementation costs are high, the local authority will always close the road for through traffic.

c. Leaving authority over traffic restrictions to the local government implies that road access will be denied to through traffic even when it is socially optimal not to do so.

\subsection{A restriction on through traffic for trucks only}

We reconsider the issue of restricting access to the local road for through traffic, but now assume that the restriction only applies to trucks, not to cars. Note that this is a common policy in many local communities throughout Europe. ${ }^{10}$

To get as transparent results as possible, we make some strong assumptions. First, as before, we assume neither tolls nor other traffic calming measures are in place. Second, suppose that there is only truck traffic from $O$ to $D$, so there is no truck traffic having the local community as final destination (this would typically not be restricted, because it consists of local deliveries). The local population will therefore only suffer from trucks diverted from the main to the local road. As before, let total demand from $O$ to $D$ be fixed, and assume that a constant fraction $\eta$ of this demand comes from cars, the remainder consists of trucks ${ }^{11}$ :

$$
\bar{X}_{O D}=\bar{X}_{O D}^{c}+\bar{X}_{O D}^{t} ; \quad \eta=\frac{\bar{X}_{O D}^{c}}{\bar{X}_{O D}^{c}+\bar{X}_{O D}^{t}} .
$$

The superscripts $c, t$ refer to cars and trucks, respectively. We further assume behavior of cars and trucks is the same in the sense that, if there are no access restrictions, the share of diverted trucks to the local road is also equal to $\eta$ :

\footnotetext{
${ }^{10}$ In related work, we considered two examples (one in the center of Leuven, one in the Ghent port area) of such truck access restrictions through local communities, and evaluated their costs and benefits. In both cases, it was found that the costs exceeded the benefits. Details are available on request.

${ }^{11}$ We could express total demand in terms of car equivalents, assuming that a truck counts for more than one car. To keep the analytics simple, we did not do so. It does not affect the interpretation of the results.
} 


$$
X_{O D}^{y}=X_{O D}^{y, c}+X_{O D}^{y, t} ; \quad \eta=\frac{X_{O D}^{y, c}}{X_{O D}^{y, c}+X_{O D}^{y, t}} .
$$

If initially there are only trucks $(\eta=0)$, then restricting access for trucks brings us back in the case of a full access restriction of Section 6.1. If there are initially only cars $(\eta=1)$, then the ban on trucks has no effect.

A last assumption we make is that a truck diverted though the local community causes more local nuisance than a car. The total external cost for the local community caused by cars and trucks together is given by:

$$
\lambda_{c} \theta_{c}\left(X_{O D}^{y, c}+(1+\rho) X_{O C}+\bar{Y}_{L D}\right)+\lambda_{t} \theta_{t}\left(X_{O D}^{y, t}\right),
$$

where $\lambda_{c} \theta_{c}<\lambda_{t} \theta_{t}$.

Before turning to the welfare comparison let us analyze the effect of the truck access restriction on traffic flows on the network. We have $X_{O D}^{y, t}=0$ or, equivalently, $X_{O D}^{y}=X_{O D}^{y, c}$. The user equilibrium that will allocate traffic flows across the network is now described by the system:

$$
\begin{aligned}
& \alpha_{x}+\beta_{x}\left(\bar{X}_{O D}-X_{O D}^{y}\right)=\alpha_{y}+\beta_{y}\left(X_{O D}^{y}+(1+\rho) X_{O C}+\bar{Y}_{L D}\right) \\
& a-b(1+\rho) X_{O C}=\alpha_{y}+\beta_{y}\left(X_{O D}^{y}+(1+\rho) X_{O C}+\bar{Y}_{L D}\right)
\end{aligned}
$$

Solving this system yields:

$$
\begin{aligned}
& X_{O D}^{y, N T}=\left(\frac{1+\rho}{\Delta}\right)\left\{\bar{X}_{O D}\left[\beta_{x}\left(b+\beta_{y}\right)\right]-\bar{Y}_{L D} b \beta_{y}+b\left(\alpha_{x}-\alpha_{y}\right)-\beta_{y}\left(a-\alpha_{x}\right)\right\} \\
& X_{O C}^{N T}=\left(\frac{-1}{\Delta}\right)\left\{\beta_{x} \beta_{y}\left(\bar{X}_{O D}+\bar{Y}_{L D}\right)-\beta_{x}\left(a-\alpha_{y}\right)-\beta_{y}\left(a-\alpha_{x}\right)\right\}
\end{aligned}
$$

where the superscript ' $N T$ ' refers to the case 'no trucks', and

$$
\Delta=(1+\rho)\left[\beta_{x} b+\left(b+\beta_{x}\right) \beta_{y}\right]>0 .
$$

In the absence of access restrictions, the equilibrium traffic flows (the superscript ' $U$ ' again refers to the initial situation) are just given by expressions (6), but taking into account that both the toll and traffic calming were assumed to be zero. Using these assumptions in (6), we have:

$$
\begin{aligned}
& X_{O D}^{y, U}=\left(\frac{1+\rho}{\Delta}\right)\left\{\bar{X}_{O D}\left[\beta_{x}\left(b+\beta_{y}\right)\right]-\bar{Y}_{L D} b \beta_{y}+b\left(\alpha_{x}-\alpha_{y}\right)-\beta_{y}\left(a-\alpha_{x}\right)\right\} \\
& X_{O C}^{U}=\left(\frac{-1}{\Delta}\right)\left\{\beta_{x} \beta_{y}\left(\bar{X}_{O D}+\bar{Y}_{L D}\right)-\beta_{x}\left(a-\alpha_{y}\right)-\beta_{y}\left(a-\alpha_{x}\right)\right\}
\end{aligned}
$$


Note that total diverted traffic $X_{O D}^{y, U}$ via $y$ consists of fractions $\eta,(1-\eta)$ of cars and trucks, respectively.

It immediately follows from the right-hand sides of (35) and (36) that total traffic on the two routes is exactly the same with and without the ban on trucks on the local road:

$$
X_{O D}^{y, U}=X_{O D}^{y, N T} ; \quad X_{O C}^{U}=X_{O C}^{N T} .
$$

Total traffic via $x$ and $y$ therefore do not change due to the truck access restriction. The only effect on traffic flows is that traffic via $y$ now only consists of cars; trucks all go via the main road. This simple result is a consequence of assuming that traffic allocation is subject to the Wardrop principle. Of course, if the two roads would be considered imperfect substitutes by car and truck drivers, the result that traffic levels do not change would not hold.

Finally, turn to the welfare comparison. In the case of truck access restrictions, federal and local welfare are:

$$
\begin{gathered}
W^{N T}(f)=\frac{b}{2}\left[(1+\rho) X_{O C}^{N T}\right]^{2}-\left[\alpha_{x}+\beta_{x}\left(\bar{X}_{O D}-X_{O D}^{y, N T}\right)\right]\left(\bar{X}_{O D}+\bar{Y}_{L D}\right) \\
-\lambda_{c} \theta_{c}\left(X_{O D}^{y, N T}+(1+\rho) X_{O C}^{N T}+\bar{Y}_{L D}\right)
\end{gathered}
$$

Note that in the absence of trucks the local externality is only due to cars passing through the local community.

Federal and local welfare in the initial situation without the ban on trucks can be written as, respectively:

$$
\begin{gathered}
W^{U}(f)=\frac{b}{2}\left[(1+\rho) X_{O C}^{U}\right]^{2}-\left[\alpha_{x}+\beta_{x}\left(\bar{X}_{O D}-X_{O D}^{y, U}\right)\right]\left(\bar{X}_{O D}+\bar{Y}_{L D}\right) \\
-\lambda_{c} \theta_{c}\left(X_{O D}^{y, U}+(1+\rho) X_{O C}^{U}+\bar{Y}_{L D}\right)-\lambda_{t} \theta_{t}\left(X_{O D}^{y, U}\right) \\
W^{U}(l)=\frac{b}{2} \frac{1+\rho}{\rho}\left(Y_{L C}^{U}\right)^{2}-G C_{y}\left(\bar{Y}_{L D}\right)-\lambda_{c} \theta_{c}\left(X_{O D}^{y, c}+(1+\rho) X_{O C}^{U}+\bar{Y}_{L D}\right)-\lambda_{t} \theta_{t}\left(X_{O D}^{y, t}\right)
\end{gathered}
$$

Total external costs imposed on the local population are now due to both cars and trucks passing via the local road $y$.

Comparing welfare is easy. Since the traffic levels are unchanged between the initial situation and the situation with a local ban on trucks (see (37)), subtracting (39a) from (38a) and (39b) from (38b), we find

$$
\begin{aligned}
& W^{N T}(f)-W^{U}(f)=\lambda_{t} \theta_{t}\left(X_{O D}^{y, t}\right)>0 \\
& W^{N T}(l)-W^{U}(l)=\lambda_{t} \theta_{t}\left(X_{O D}^{y, t}\right)>0
\end{aligned}
$$


The implication is clear. Contrary to what we found when we restricted access to all through traffic via $y$ (see Proposition 5), we do not see a conflict between local and federal authorities: both will want to impose a ban on through traffic by trucks. The reason is that both governments do care for traffic externalities imposed upon the local population and, unlike in the case of a ban on all through traffic, there is no loss in consumer surplus for price-sensitive demand. Do note that this strong conclusion hinges on crucial assumptions: we ignored implementation costs, and we assumed perfect substitutability between roads $x$ and $y$, allowing us to invoke the Wardrop condition.

\section{Proposition 6. Both the federal and the local government will agree on imposing a ban on trucks through the local community.}

Although the model used was very stylized, Propositions 5 and 6 together may provide one explanation for the empirical observation that we see more frequent access restrictions for truck traffic only than overall access restrictions on all through traffic. Although there are several countries where restricted access on all types of traffic can be implemented by local governments, they can typically only decide this unilaterally for very local roads, so their capacity to handle through traffic is limited.

\section{Limitations and extensions}

The network studied in this paper was very simple; moreover, we deliberately focused on very specific policy questions. In this section we briefly discuss possible extensions and highlight a few obvious limitations.

First, we can extend the simple network used in this paper to see whether the 'race to the top in traffic calming' that was observed in earlier literature can be generalized to a setting with congested roads and the possibility of imposing tolls. In a recent paper, Proost and Westin (2016) studied a model with two parallel roads where two different governments each control traffic calming on one road; they assumed the roads were uncongested. They show that this results in a race to the top, in the sense that both authorities will invest too much in traffic calming compared to the social optimum. In Appendix 5 we extend the network we considered in this paper with a second road parallel to the main highway. This is quite common in reality, in the sense that municipalities typically develop on both sides of the highway. We show that 
the race to the top in traffic calming is still preserved; the reaction functions of the two regional authorities are upward sloping in traffic calming, and both local governments put too many speed bumps or traffic lights as compared to the social optimum. Moreover, as we also find that traffic calming on both roads is positively affected by the toll on the main road; traffic calming will be used even more intensively than in a setting with just two parallel roads. We refer to Appendix 5 for details.

Second, we could use the model to study an extreme case of access restrictions, viz., car-free zones within municipalities. This would imply the restriction that neither diverted through traffic nor traffic that has the local community as final destination can pass though the local community; we have $X_{O D}^{y}=X_{O C}=Y_{L C}=\bar{Y}_{L D}=0$. Of course, this would require the introduction of extra transport options so as to allow this traffic to reach their destinations (bike paths, public transport, bypass roads avoiding the local community, etc.), complicating the technical analysis. In the simplest possible setting, one could assume that for each type of traffic there is an alternative available at a cost that exceeds the generalized cost of using $y$. We then easily show that the same principles that drive the results of the current paper also apply to carfree zones. Most importantly, the federal government is generally less inclined to impose such zones than the local government. From a federal welfare perspective, we will therefore have too many car-free zones.

Third, the model can be extended to allow for public transport. This, however, would also not fundamentally change the main results from the analysis. For example, suppose a public transport line exists between $O$ and $D$. Depending on how public transit is priced (and this may depend on whether it is operated by the federal authority or by an independent agency), it will affect congestion on the main road. But, although it may make the problem less severe, public transport availability would not resolve the traffic diversion problem faced by the local authority. Qualitatively, all relevant implications we derived will continue to hold.

Finally, we assumed that car traffic diverted from the main road to the local municipality imposed local accident, noise and pollution externalities on the local population. The behavior of the local population was not modeled, however. For example, the externality could involve accident risks imposed upon bikers and pedestrians on the municipal road, but their adaptive behavior was not modelled. Moreover, we ignored possible long-run effects and implicitly assumed that this population was fixed. 


\section{Conclusions}

We studied a simple network consisting of a main road and a local road passing through a smaller community. We analyzed the interaction between tolling the main road, diverted traffic and the use of various traffic calming measures by the local authorities. We showed that vertical competition between governments implies tolls and traffic calming measures that are both too high compared to the second-best social optimum. Moreover, given intensive use of local traffic calming measures by local governments, we found that it may not be a good idea for the federal government to toll the main road: unless congestion on the main road is severe and accident risks for the population of the small town are very low, imposing a toll on the main road is in fact welfare-reducing. We further showed that the existence of diverted traffic from the main road to the local community gives the latter strong incentives to close the local road for through traffic, even when it is socially undesirable to do so. In this sense, granting authority over local traffic calming measures to local governments may be socially undesirable. If the restriction only applies to through traffic by trucks, the conflict between federal and local authorities disappears: both will agree on prohibiting access to trucks, unless they have the local town as final destination. Finally, we argued that some of the inefficiencies of vertical competition between local and federal governments can be avoided by introducing a hierarchy of roads and negotiated decisions by independent agencies. 


\section{References}

Anas A., Lindsey R.,2011, Reducing urban road transportation externalities: road pricing in theory and in practice, Review of Environmental Economics and Policy 5(1), 66-88.

Bento A., Goulder L., Jacobsen M. and R. von Haefen, 2009. Distributional and Efficiency Impacts of Increased US Gasoline Taxes, American Economic Review 99 (3), 1-37.

Davis, L.W.,(2008), The Effect of Driving Restrictions on Air Quality in Mexico City, Journal of Political Economy, vol. 116, no. 1, 38-81

De Borger, B. , S. Proost, 2012b. Transport policy competition between governments: a selective survey of the literature, Economics of Transportation 1, 35-48.

De Borger, B., Proost, S. (2013). Traffic externalities in cities: the economics of speed bumps, low emission zones and city bypasses. Journal of Urban Economics, 76, 53-70.

De Borger B., Proost S. (2016,a). The political economy of pricing and capacity decisions for congestible local public goods in a federal state. International Tax and Public Finance, 23(05), 934-959.

De Borger B., Proost S. (2016,b). Can we leave road pricing to the regions? The role of institutional constraints. Regional Science and Urban Economics, 60, 208-222.

De Borger B., Proost S., Van Dender K. (2005). Congestion and tax competition in a parallel network. European economic review, 49 (8), 2013-2040.

De Borger, B., Dunkerley, F. and S. Proost (2007), Strategic investment and pricing decisions in a congested transport corridor. Journal of Urban Economics 62, 294-316.

de Palma, A. and R. Lindsey (2000), Private toll roads: competition under various ownership regimes, The Annals of Regional Science 34, 13-35.

Elvik, R., 2001. Area-wide urban traffic calming schemes: a meta-analysis of safety effects, Accident Analysis and Prevention 33, 327-336.

Evers, R., Proost, S. (2015). Optimizing intersections. Transportation Research Part B, 71, 100119.

Graham-Rowe E. , Skippon S., Gardner B., Abraham C.(2011) , Can we reduce car use and, if so, how? A review of available evidence, Transportation Research Part A 45, 401-418

Levinson, D. (2001), Why states toll - An empirical model of finance choice, Journal of Transport Economics and Policy, 35, 2, 223-238.

Nie, Y.M. (2017) On the potential remedies for license plate rationing, http://dx.doi.org/10.1016/j.ecotra.2017.01.001

Nitzsche E., Tscharaktschiew S., (2013) Efficiency of speed limits in cities: A spatial computable general equilibrium assessment, Transportation Research Part A 56, 23-48

Parry, I and K. Small, 2005. Does Britain of the United States have the right gasoline tax, American Economic Review 95, 1276-1289.

Proost, S., Westin, J. (2015). Race to the top in traffic calming. Papers in Regional Science.

Ubbels, B. and E. Verhoef (2008), Governmental Competition in Road Charging and Capacity Choice, Regional Science and Urban Economics, 38, 174-190. 
Van Benthem, A. (2015), What is the optimal speed limit on freeways, Journal of Public Economics 124, 44-62.

Van Nieuwenhuysen, M.J. and H. Khreis (2016), Car-free cities: pathways to healthy urban living, Environment International 96, 252,261.

Wolff, H., Perry, L., 2010. Trends in clean air legislation in Europe: particulate matter and low emission zones. Review of Environmental Economics and Policy 4 (2), 293-308. 
Write (15) as an implicit function $\phi\left(Z, \tau_{x}\right)=0$ :

$$
\begin{gathered}
\phi\left(Z, \tau_{x}\right)=-\left[\left(\beta_{y}+\delta Z\right)\left(Y_{L C}+\bar{Y}_{L D}\right)+\lambda \theta(1-\gamma Z)\right]\left(\frac{\partial T^{y}}{\partial Z}\right)+\lambda \theta \gamma T^{y} \\
-c Z-\delta T^{y}\left(Y_{L C}+\bar{Y}_{L D}\right)=0
\end{gathered}
$$

Differentiating we have:

$$
\begin{aligned}
\frac{\partial \phi\left(Z, \tau_{x}\right)}{\partial \tau_{x}}=-\left[\left(\beta_{y}+\delta Z\right)\left(Y_{L C}+\bar{Y}_{L D}\right)\right. & +\lambda \theta(1-\gamma Z)]\left(\frac{\partial^{2} T^{y}}{\partial Z \partial \tau_{x}}\right) \\
-\left\{\left(\beta_{y}+\delta Z\right)\left(\frac{\partial T^{y}}{\partial Z}\right)+\delta T^{y}\right\} \frac{\partial Y_{L C}}{\partial \tau_{x}} & -\left[\delta\left(Y_{L C}+\bar{Y}_{L D}\right)-\lambda \theta \gamma\right] \frac{\partial T^{y}}{\partial \tau_{x}}
\end{aligned}
$$

To show that this is unambiguously positive, first note that (A1.1) implies:

$$
-\delta\left(Y_{L C}+\bar{Y}_{L D}\right)+\lambda \theta \gamma=\frac{1}{T^{y}}\left\{[Q]\left(\frac{\partial T^{y}}{\partial Z}\right)+c Z\right\}
$$

where

$$
[Q]=\left[\left(\beta_{y}+\delta Z\right)\left(Y_{L C}+\bar{Y}_{L D}\right)+\lambda \theta(1-\gamma Z)\right]
$$

Then use (A1.3)-(A1.4) and simple rearrangements to rewrite (A1.2) as:

$$
\begin{aligned}
\frac{\partial \phi\left(Z, \tau_{x}\right)}{\partial \tau_{x}}=-[Q] & \left\{\left(\frac{\partial^{2} T^{y}}{\partial Z \partial \tau_{x}}\right)-\frac{1}{T^{y}} \frac{\partial T^{y}}{\partial \tau_{x}} \frac{\partial T^{y}}{\partial Z}\right\} \\
& -\left\{\left(\beta_{y}+\delta Z\right)\left(\frac{\partial T^{y}}{\partial Z}\right)+\delta T^{y}\right\} \frac{\partial Y_{L C}}{\partial \tau_{x}}+c Z \frac{1}{T^{y}} \frac{\partial T^{y}}{\partial \tau_{x}}
\end{aligned}
$$

Algebra shows that the first term between the brackets equals zero. To see this, differentiate (7) and use (7) and (9) to find:

$$
\left(\frac{\partial^{2} T^{y}}{\partial Z \partial \tau_{x}}\right)-\frac{1}{T^{y}} \frac{\partial T^{y}}{\partial \tau_{x}} \frac{\partial T^{y}}{\partial Z}=-\frac{(1+\rho)^{2} \delta b\left(b+\beta_{x}\right)}{\Delta^{2}}+\frac{1}{T^{y}} \frac{(1+\rho) b}{\Delta} \frac{(1+\rho)^{2} \delta}{\Delta^{2}}\left[\left(b+\beta_{x}\right)(H)\right]
$$

Next use (5), (6) and (8) to get $T^{y}=\frac{1+\rho}{\Delta}(\mathrm{H})$. Substituting this result and working out yields: 


$$
\left(\frac{\partial^{2} T^{y}}{\partial Z \partial \tau_{x}}\right)-\frac{1}{T^{y}} \frac{\partial T^{y}}{\partial \tau_{x}} \frac{\partial T^{y}}{\partial Z}=0
$$

Finally, substitute (A1.6) in (A1.5):

$$
\frac{\partial \phi\left(Z, \tau_{x}\right)}{\partial \tau_{x}}=-\left\{\left(\beta_{y}+\delta Z\right)\left(\frac{\partial T^{y}}{\partial Z}\right)+\delta T^{y}\right\} \frac{\partial Y_{L C}}{\partial \tau_{x}}+c Z \frac{1}{T^{y}} \frac{\partial T^{y}}{\partial \tau_{x}}
$$

This is necessarily positive (see (9) and (22)).

\section{Appendix 2. Determining the slope of the federal government's reaction function}

Write (17) as an implicit function $\varphi\left(Z, \tau_{x}\right)=0$ :

$$
\begin{aligned}
\varphi\left(Z, \tau_{x}\right)=\left(\tau_{x}-\right. & \left.\beta_{x}\left(\bar{X}_{O D}-X_{O D}^{y}\right)\right) \frac{\partial X_{O D}^{y}}{\partial \tau_{x}} \\
& +\left\{\left[\left(\beta_{y}+\delta Z\right)\left(T^{y}\right)+\lambda \theta(1-\gamma Z)\right]\left[\frac{\partial T^{y}}{\partial \tau_{x}}\right]\right\}=0
\end{aligned}
$$

This implicitly defines the federal government's reaction function $\tau_{x}^{r}(Z)$. We calculate the effect of traffic calming by the local community on the federal toll as:

$$
\frac{d \tau_{x}^{r}(Z)}{d Z}=-\frac{\frac{\partial \varphi\left(Z, \tau_{x}\right)}{\partial Z}}{\frac{\partial \varphi\left(Z, \tau_{x}\right)}{\partial \tau_{x}}}
$$

By the second-order condition of the federal government's optimization problem we have $\frac{\partial \varphi\left(Z, \tau_{x}\right)}{\partial \tau_{x}}>0$ (note that $\varphi\left(Z, \tau_{x}\right)=-\frac{\partial W^{f}}{\partial \tau_{x}}$, hence $\frac{\partial \varphi\left(Z, \tau_{x}\right)}{\partial \tau_{x}}=-\frac{\partial^{2} W^{f}}{\partial \tau_{x}^{2}}>0$ ).

The numerator can be written as:

$$
\begin{gathered}
\frac{\partial \varphi\left(Z, \tau_{x}\right)}{\partial Z}=\left(\tau_{x}-\beta_{x}\left(\bar{X}_{O D}-X_{O D}^{y}\right)\right) \frac{\partial^{2} X_{O D}^{y}}{\partial \tau_{x} \partial Z}+\beta_{x} \frac{\partial X_{O D}^{y}}{\partial \tau_{x}} \frac{\partial X_{O D}^{y}}{\partial Z} \\
+\left\{\delta\left(T^{y}\right)+\left(\beta_{y}+\delta Z\right)\left[\frac{\partial T^{y}}{\partial Z}\right]-\lambda \theta \gamma\right\}\left[\frac{\partial T^{y}}{\partial \tau_{x}}\right] \\
+\left[\left(\beta_{y}+\delta Z\right)\left(T^{y}\right)+\lambda \theta(1-\gamma Z)\right]\left[\frac{\partial^{2} T^{y}}{\partial \tau_{x} \partial Z}\right]
\end{gathered}
$$


Using (A2.1), we reformulate this equation as:

$$
\begin{aligned}
& \frac{\partial \varphi\left(Z, \tau_{x}\right)}{\partial Z}= \\
& \left\{\left[\left(\beta_{y}+\delta Z\right)\left(T^{y}\right)+\lambda \theta(1-\gamma Z)\right]\right\}\left\{\frac{\partial^{2} T^{y}}{\partial \tau_{x} \partial Z}-\frac{\frac{\partial T^{y}}{\partial \tau_{x}}}{\frac{\partial X_{O D}^{y}}{\partial \tau_{x}}} \frac{\partial^{2} X_{O D}^{y}}{\partial \tau_{x} \partial Z}\right\} \\
& \quad+\beta_{x} \frac{\partial X_{O D}^{y}}{\partial \tau_{x}} \frac{\partial X_{O D}^{y}}{\partial Z}+\left\{\delta\left(T^{y}\right)+\left(\beta_{y}+\delta Z\right) \frac{\partial T^{y}}{\partial Z}\right\} \frac{\partial T^{y}}{\partial \tau_{x}}-\lambda \theta \gamma \frac{\partial T^{y}}{\partial \tau_{x}}
\end{aligned}
$$

We can show that this expression will always be negative. To do so, we first use (7), (8), and (9) to find:

$$
\begin{aligned}
& \left\{\frac{\frac{\partial T^{y}}{\partial \tau_{x}}}{\frac{\partial X_{O D}^{y}}{\partial \tau_{x}}}\right\} \frac{\partial^{2} X_{O D}^{y}}{\partial \tau_{x} \partial Z}=-\left(\frac{1+\rho}{\Delta}\right)^{2} \frac{\delta b^{3}}{b+\beta_{y}+\delta z} \\
& \frac{\partial^{2} T^{y}}{\partial \tau_{x} \partial Z}=-\left(\frac{1+\rho}{\Delta}\right)^{2} \delta b\left(b+\beta_{x}\right)
\end{aligned}
$$

These results and simple algebra then immediately show:

$$
\left\{\frac{\partial^{2} T^{y}}{\partial \tau_{\chi} \partial Z}-\frac{\frac{\partial T^{y}}{\partial \tau_{x}}}{\frac{\partial X_{O D}^{y}}{\partial \tau_{x}}} \frac{\partial^{2} X_{O D}^{y}}{\partial \tau_{x} \partial Z}\right\}<0
$$

Next, we have (see (7), (9) and (22):

$$
\begin{aligned}
& \frac{\partial X_{O D}^{y}}{\partial \tau_{x}} \frac{\partial X_{O D}^{y}}{\partial Z}=-\left(\frac{1+\rho}{\Delta}\right)^{3} \delta b\left(b+\beta_{y}+\delta \mathrm{z}\right)(\mathrm{H}) \\
& \delta\left(T^{y}\right)+\left(\beta_{y}+\delta Z\right)\left[\frac{\partial T^{y}}{\partial Z}\right]=\left(\frac{1+\rho}{\Delta}\right)^{2} \delta b \beta_{x}(\mathrm{H})
\end{aligned}
$$

Using these results we can easily show:

$$
\beta_{x} \frac{\partial X_{O D}^{y}}{\partial \tau_{x}} \frac{\partial X_{O D}^{y}}{\partial Z}+\left\{\delta\left(T^{y}\right)+\left(\beta_{y}+\delta Z\right) \frac{\partial T^{y}}{\partial Z}\right\} \frac{\partial T^{y}}{\partial \tau_{x}}<0
$$


Putting all these results together in (A2.3) we have

$$
\frac{\partial \varphi\left(Z, \tau_{x}\right)}{\partial Z}<0
$$

\section{Appendix 3. A leader-follower model}

We assume that the local authority decides on traffic calming, knowing that the federal level will follow via her reaction function $\tau_{x}^{r}(Z)$. Reconsidering the problem for the local government defined in section 4.1, but taking into account that $\tau_{x}=\tau_{x}^{r}(Z)$, the first-order condition gives, after algebra:

$$
\begin{aligned}
& -\left[\left(\beta_{y}+\delta Z\right)\left(Y_{L C}+\bar{Y}_{L D}\right)+\lambda \theta(1-\gamma Z)\right]\left(\frac{\partial T^{y}}{\partial Z}\right) \\
& +\lambda \theta \gamma T^{y}-c Z-\delta T^{y}\left(Y_{L C}+\bar{Y}_{L D}\right) \\
& -\frac{\partial \tau_{x}^{r}}{\partial Z}\left\{\left(\beta_{y}+\delta Z\right)\left(Y_{L C}+\bar{Y}_{L D}\right)+\lambda \theta(1-\gamma Z)\right\}\left(\frac{\partial T^{y}}{\partial \tau_{x}}\right)=0
\end{aligned}
$$

The first two lines capture the first-order condition for the optimal Z, given an arbitrary toll, see (15) above. The final term reduces the benefit of raising traffic calming, because traffic calming leads to higher tolls. Lower benefits of traffic calming imply that the local level will reduce $Z$. Since the equilibrium is necessarily situated on the reaction function of the federal government we have a lower $Z$ and a lower toll compared to Nash equilibrium.

\section{Appendix 4. Proofs of (26) and (29)}

\section{Proof of (26)}

To show (26), first note that the iso-generalized cost lines on road $y$ in $\left(\tau_{x}, Z\right)$-space have a negative slope. To see this note that:

$$
d G C_{y}=d\left(\alpha_{y}+\left(\beta_{y}+\delta Z\right) T^{y}\right)=\left[\left(\beta_{y}+\delta Z\right) \frac{\partial T^{y}}{\partial \tau_{x}}\right] d \tau_{x}+\left[\delta T^{y}+\left(\beta_{y}+\delta Z\right) \frac{\partial T^{y}}{\partial Z}\right] d Z=0
$$

Hence: 


$$
\frac{d \tau_{x}}{d Z}=-\frac{\left[\delta T^{y}+\left(\beta_{y}+\delta Z\right) \frac{\partial T^{y}}{\partial Z}\right]}{\left[\left(\beta_{y}+\delta Z\right) \frac{\partial T^{y}}{\partial \tau_{x}}\right]}<0
$$

The generalized cost rises further from the origin. Jointly these observations imply that the generalized cost is necessarily higher at the Nash equilibrium than in the case 'toll only': $G C^{N E}>G C^{0}$.

Further note that in equilibrium

$$
a-b(1+\rho) X_{O C}=G C_{y}
$$

The right hand side is higher at the Nash equilibrium. This must imply that we have

$$
X_{O C}^{N E}<X_{O C}^{0}
$$

Moreover, the higher generalized costs at the Nash equilibrium further implies:

$$
\beta_{y}\left(1-\gamma Z^{N E}\right) T^{y, N E}>\beta_{y} T^{y, 0}
$$

From this inequality we derive

$$
T^{y, N E}>T^{y, 0} .
$$

Using the definitions of the total traffic flow via road $y$, this together with $X_{O C}^{N E}<X_{O C}^{0}$ necessarily implies that

$$
X_{O D}^{y, N E}>X_{O D}^{y, 0}
$$

\section{Proof of (29)}

By the same argument as above, we have $G C^{N E}>G C^{1}$ and $X_{O C}^{N E}<X_{O C}^{1}$. Moreover, the higher generalized costs at the Nash equilibrium implies:

$$
\beta_{y}\left(1-\gamma Z^{N E}\right) T^{y, N E}>\beta_{y}\left(1-\gamma Z^{1}\right) T^{y, 0}
$$

Noting that $Z^{N E}>Z^{1}$ this in turn implies $T^{y, N E}>T^{y, 1}$. Using the definitions of the total traffic flow via road $y$, this together with $X_{O C}^{N E}<X_{O C}^{1}$ necessarily implies that 


$$
X_{O D}^{y, N E}>X_{O D}^{y, 1}
$$

\section{Appendix 5. Extension to a three-road network}

Consider a network consisting of one major road and two parallel local roads. To focus on the role of diverted traffic through the local municipalities, we simplify the model and assume traffic with local destination is zero: $X_{O C}^{1}=X_{O C}^{2}=\bar{Y}_{L D}^{1}=\bar{Y}_{L D}^{2}=0$. We denote traffic diverted from the main road to the two local roads by $X_{O D}^{y_{1}}, X_{O D}^{y_{2}}$, respectively. The generalized costs on the various roads are therefore given by

$$
\begin{aligned}
& G C_{x}=\alpha_{x}+\beta_{x}\left(\bar{X}_{O D}-X_{O D}^{y_{1}}-X_{O D}^{y_{2}}\right)+\tau_{x} \\
& G C_{y_{1}}=\alpha_{y}+\left(\beta_{y}+\delta Z_{1}\right)\left(X_{O D}^{y_{1}}\right) \\
& G C_{y_{2}}=\alpha_{y}+\left(\beta_{y}+\delta Z_{2}\right)\left(X_{O D}^{y_{2}}\right)
\end{aligned}
$$

The user equilibrium is described by the system:

$$
\begin{aligned}
& \alpha_{x}+\beta_{x}\left(\bar{X}_{O D}-X_{O D}^{y_{1}}-X_{O D}^{y_{2}}\right)+\tau_{x}=\alpha_{y}+\left(\beta_{y}+\delta Z_{1}\right)\left(X_{O D}^{y_{1}}\right) \\
& \alpha_{y}+\left(\beta_{y}+\delta Z_{1}\right)\left(X_{O D}^{y_{1}}\right)=\alpha_{y}+\left(\beta_{y}+\delta Z_{2}\right)\left(X_{O D}^{y_{2}}\right)
\end{aligned}
$$

Solving for the equilibrium traffic levels yields the following results:

$$
\begin{aligned}
X_{O D}^{y_{1}} & =\frac{1}{\mathrm{~K}}\left(\beta_{y}+\delta \mathrm{Z}_{2}\right)\left(\alpha_{x}-\alpha_{y}+\beta_{x} \bar{X}_{O D}+\tau_{x}\right) \\
X_{O D}^{y_{2}} & =\frac{1}{\mathrm{~K}}\left(\beta_{y}+\delta \mathrm{Z}_{1}\right)\left(\alpha_{x}-\alpha_{y}+\beta_{x} \bar{X}_{O D}+\tau_{x}\right) \\
& \text { where } \mathrm{K}=\beta_{x}\left[2 \beta_{y}+\delta\left(Z_{1}+Z_{2}\right)\right]+\left(\beta_{y}+\delta \mathrm{Z}_{1}\right)\left(\beta_{y}+\delta \mathrm{Z}_{2}\right)
\end{aligned}
$$

It is easy to show (and entirely as expected) that, for given total traffic demand, the 'availability' of a second local road reduces congestion on the main road, as more traffic is diverted to the local roads. Moreover, there is also less congestion on each of the two roads separately than on a single local road.

Our simplifying assumptions imply that there is no price-responsive demand, so that governments decide on the policy measure they control by minimizing total social costs. The authority controlling traffic calming $Z_{1}$ on the first local road faces therefore the following problem: 


$$
\operatorname{Min}_{Z_{1}} \quad 0.5 c\left(Z_{1}\right)^{2}+\lambda \theta\left(1-\gamma Z_{1}\right) X_{O D}^{y_{1}}
$$

The first term is the implementation cost of the traffic calming measure, the second term the external cost imposed on the local population. The first-order condition reads:

$$
c Z_{1}+\lambda \theta\left(1-\gamma Z_{1}\right) \frac{\partial X_{O D}^{y_{1}}}{\partial Z_{1}}-\lambda \theta \gamma X_{O D}^{y_{1}}=0
$$

It follows:

$$
\begin{aligned}
& \frac{d Z_{1}}{d \tau_{x}}=-\frac{\lambda \theta\left(1-\gamma Z_{1}\right) \frac{\partial^{2} X_{O D}^{y_{1}}}{\partial Z_{1} \partial \tau_{x}}-\lambda \theta \gamma \frac{\partial X_{O D}^{y_{1}}}{\partial \tau_{x}}}{\Delta_{1}} \\
& \frac{d Z_{1}}{d Z_{2}}=-\frac{\lambda \theta\left(1-\gamma Z_{1}\right) \frac{\partial^{2} X_{O D}^{y_{1}}}{\partial Z_{1} \partial Z_{2}}-\lambda \theta \gamma \frac{\partial X_{O D}^{y_{1}}}{\partial Z_{2}}}{\Delta_{1}}
\end{aligned}
$$

In these expressions, $\Delta_{1}>0$ by the second-order condition.

Algebra further shows:

$$
\begin{aligned}
& \frac{\partial X_{O D}^{y_{1}}}{\partial \tau_{x}}=\frac{\beta_{y}+\delta Z_{2}}{(\mathrm{~K})}>0 \\
& \frac{\partial X_{O D}^{y_{1}}}{\partial Z_{2}}=\frac{\delta \beta_{x}\left(\beta_{y}+\delta Z_{1}\right)\left(\alpha_{x}-\alpha_{y}+\beta_{x} \bar{X}_{O D}+\tau_{x}\right)}{(\mathrm{K})^{2}}>0 \\
& \frac{\partial^{2} X_{O D}^{y_{1}}}{\partial Z_{1} \partial \tau_{x}}=-\frac{\left(\beta_{y}+\delta Z_{2}\right)\left[\delta\left(\beta_{x}+\beta_{y}+\delta Z_{2}\right)\right]}{(\mathrm{K})^{2}}<0 \\
& \frac{\partial^{2} X_{O D}^{y_{1}}}{\partial Z_{1} \partial Z_{2}}=-\frac{\delta \beta_{x}\left(\alpha_{x}-\alpha_{y}+\beta_{x} \bar{X}_{O D}+\tau_{x}\right)\left(\beta_{y}+\delta Z_{1}\right)\left(\beta_{y}+\delta Z_{2}\right)}{(\mathrm{K})^{3}}<0
\end{aligned}
$$

It immediately follows that

$$
\begin{aligned}
& \frac{d Z_{1}}{d \tau_{x}}>0 \\
& \frac{d Z_{1}}{d Z_{2}}>0
\end{aligned}
$$

Analysis for the second local authority that controls $Z_{2}$ is completely analogous. The results confirms intuition. A higher toll on the main road raises diverted traffic towards the two local roads. Moreover, more traffic calming on one local road raises traffic on the other one. In 
this sense, the analysis confirms the race to the top observed in earlier literature: reaction functions in traffic calming are upward sloping.

Lastly, consider the behavior of the federal authority controlling the toll on the main road. They minimize

$$
\begin{array}{rl}
\operatorname{Min}_{\tau_{x}} & G C_{x}\left(\bar{X}_{O D}-X_{O D}^{y_{1}}-X_{O D}^{y_{2}}\right)+G C_{y_{1}} X_{O D}^{y_{1}}+G C_{y_{2}} X_{O D}^{y_{2}} \\
& -\tau_{x}\left(\bar{X}_{O D}-X_{O D}^{y_{1}}-X_{O D}^{y_{2}}\right)+\lambda \theta\left(1-\gamma Z_{1}\right) X_{O D}^{y_{1}}+\lambda \theta\left(1-\gamma Z_{2}\right) X_{O D}^{y_{2}}
\end{array}
$$

The first order condition reads:

$$
\left[\tau_{x}-\beta_{x}\left(\bar{X}_{O D}-X_{O D}^{y_{1}}-X_{O D}^{y_{2}}\right)\right]\left(\frac{\partial X_{O D}^{y_{1}}}{\partial \tau_{x}}+\frac{\partial X_{O D}^{y_{2}}}{\partial \tau_{x}}\right)+\lambda \theta\left(1-\gamma Z_{1}\right) \frac{\partial X_{O D}^{y_{1}}}{\partial \tau_{x}}+\lambda \theta\left(1-\gamma Z_{2}\right) \frac{\partial X_{O D}^{y_{2}}}{\partial \tau_{x}}=0
$$

This shows the toll is below marginal external congestion cost on the main road. Straightforward but rather elaborate algebra shows that the effect of traffic calming on the toll is, as expected, positive. 
Copyright @ 2018 @ the author(s). Discussion papers are in draft form. This discussion paper is distributed for purposes of comment and discussion only. It may not be reproduced without permission of the copyright holder. Copies of working papers are available from the author. 